\title{
Predicting Opioid Prescribing Behaviors: Influence of an Expert Opioid-Risk Evaluation
}

Alison M. Vargovich

Follow this and additional works at: https://researchrepository.wvu.edu/etd

\section{Recommended Citation}

Vargovich, Alison M., "Predicting Opioid Prescribing Behaviors: Influence of an Expert Opioid-Risk Evaluation" (2014). Graduate Theses, Dissertations, and Problem Reports. 6866.

https://researchrepository.wvu.edu/etd/6866

This Dissertation is protected by copyright and/or related rights. It has been brought to you by the The Research Repository @ WVU with permission from the rights-holder(s). You are free to use this Dissertation in any way that is permitted by the copyright and related rights legislation that applies to your use. For other uses you must obtain permission from the rights-holder(s) directly, unless additional rights are indicated by a Creative Commons license in the record and/ or on the work itself. This Dissertation has been accepted for inclusion in WVU Graduate Theses, Dissertations, and Problem Reports collection by an authorized administrator of The Research Repository @ WVU.

For more information, please contact researchrepository@mail.wvu.edu. 
Predicting Opioid Prescribing Behaviors:

Influence of an Expert Opioid-Risk Evaluation

Alison M. Vargovich, M.S.

\author{
Dissertation submitted \\ to the Eberly College of Arts and Sciences \\ at West Virginia University \\ in partial fulfillment of the requirements for the degree of \\ Doctor of Philosophy \\ in \\ Psychology
}
Daniel W. McNeil, Ph.D., Chair
Kevin T. Larkin, Ph.D.
Jeannie Sperry, Ph.D.
Steven Kinsey, Ph.D.
L. Christopher Plein, Ph.D.
Department of Psychology

Morgantown, West Virginia

2014

Keywords: Opioids, Prescribing Behaviors, Primary Care, Chronic Pain Copyright 2014 Alison M. Vargovich, M.S. 


\author{
Abstract \\ Predicting Opioid Prescribing Behaviors: \\ Influence of an Expert Opioid-Risk Evaluation
}

Alison M. Vargovich, M.S.

Opioid analgesics have been shown to be effective for short-term pain reduction; however, chronic opioid therapy does not improve functioning, and may lead to problems with dependence and abuse. Physicians report having difficulty discerning substance abuse or drug diversion, which can lead to over- or under- prescribing, poor pain management, and may contribute to the growing number of opioid-related overdose deaths. The primary aim of this study was to determine if a psychological opioid risk evaluation influenced opioid prescribing in physicians at the West Virginia University (WVU) Family Medicine Clinic. For this retrospective study, participants were 151 ( 89 female) adult patients being considered for long-term opioid therapy. Patients participated in a psychological opioid risk evaluation, which included several questionnaires and a clinical interview. This evaluation resulted in an opioid risk level (i.e., low, low-moderate, moderate, moderate-high, high) being assigned to each patient representing clinical judgment about their potential risk for misusing or abusing opioid medication. An electronic medical record review was conducted on each patient, abstracting information about if an opioid was prescribed, in addition to several other factors, which later were included in logistic regression analyses. Patients prescribed an opioid were more likely to be married or with a long term partner and have a higher level of education. Patients not prescribed an opioid were more likely to report a higher pain rating at the time of the evaluation, a history of abuse or substance abuse, or have higher total scores for questionnaires measuring pain catastrophizing, misuse or diversion behaviors, and depression symptoms. Risk status and substance abuse history significantly predicted opioid prescribing, with a decrease in risk status resulting in an increase in opioid prescribing, and those with a history of substance abuse being less likely to be prescribed an opioid; however, substance abuse did not significantly improve the overall model and was removed. Additionally, demographic variables (i.e., age, sex, ethnicity/race) were not significant predictors of prescribing as found in other studies. These findings suggest that providing physicians with additional information about their patient's opioid abuse potential aids in prescribing decisions and may reduce prescribing bias based on demographic factors. Risk status may allow physicians to integrate evidence-based factors into their decision-making process in a simplified manner, and possibly improve patient care. Future work should continue to address physicians' prescribing perspective, accuracy of evaluations, effect on patient care, and cost analyses for the healthcare system. 


\section{Acknowledgements}

First and foremost, I would like to thank my mentor and dissertation chair, Dr. Dan McNeil, for his endless support, guidance, and patience. Your mentoring has been invaluable to my development as a psychologist. Thank you for providing all of your students the freedom to explore their areas of interest and be a part of your rich research. To Dr. Jeannie Sperry, a special thank you for taking me under your wing at Family Medicine, helping to cement my interest in pain, and being an excellent role model of a professional woman in psychology. To my other committee members, Drs. Kevin Larkin, Steve Kinsey, and Chris Plein, thank you for your feedback and guidance in making this project the best it could be. Additional thanks to all of my lab mates in the Anxiety, Psychophysiology, and Pain Research Laboratory, especially Cameron Randall and Sarah Hayes, as well as the other members of my cohort, for their support, camaraderie, and solidarity through this graduate school adventure. The past 5 years truly have been wonderful and I am very thankful to all.

Finally, to my parents, Paul and Suzanne, thank you for your constant love and support throughout my entire life and for encouraging me to continue my education. You have been an integral part of my success and have motivated me to persevere through the setbacks. I owe you more than I can give. To my siblings, Angela, Paul, Lisa, and Lauren, and their families, my life would be much quieter and less fulfilling without you; thanks for making me laugh and always

reminding me that I still am the baby, no matter my age or degree. Lastly, to my husband, Mark, thank you for making the difficult times easier, every day lighter, and providing me with unconditional support and love. 


\section{TABLE OF CONTENTS}

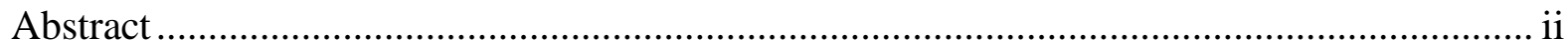

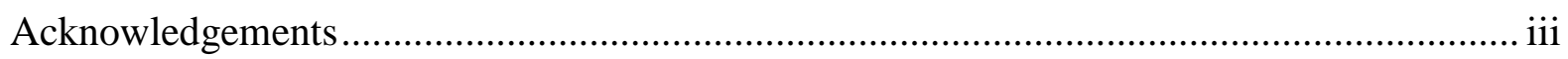

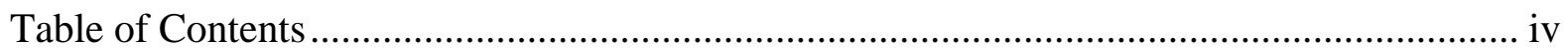

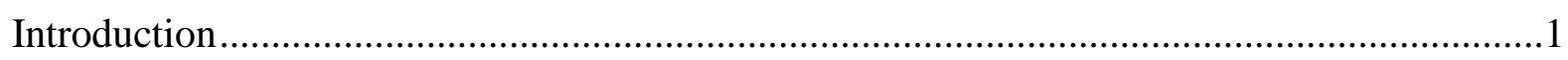

Conceptualization of Chronic Pain ................................................................

Opioid Treatment for Chronic Pain ...................................................................

Prevalence of Prescription Opioid Abuse in the U.S.............................................5

Influence of Policy in the Healthcare System and Opioid Prescribing .......................

Need for Evaluations to Determine Appropriateness ......................................... 10

Medication Prescribing Decisions and Behaviors .............................................. 12

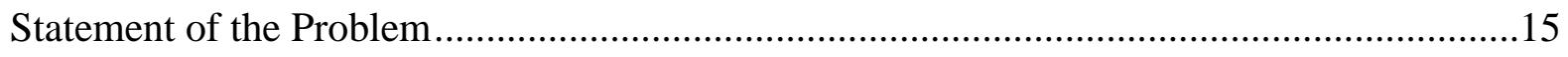

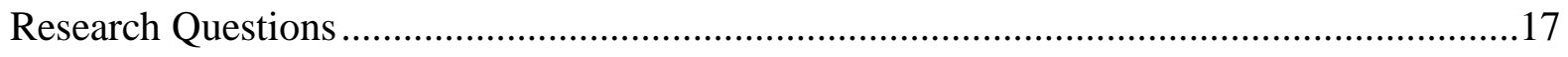

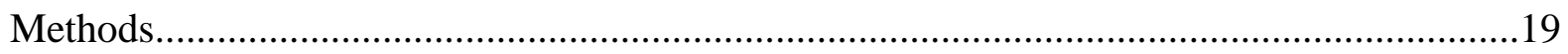

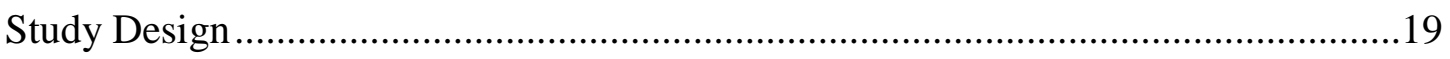

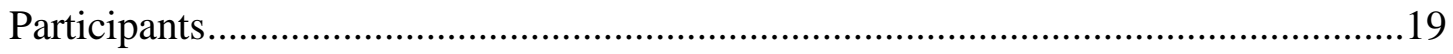

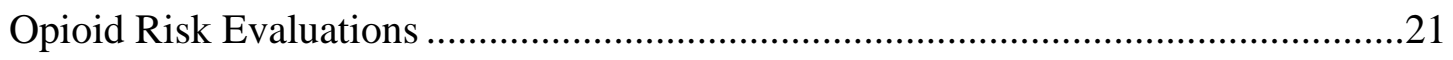

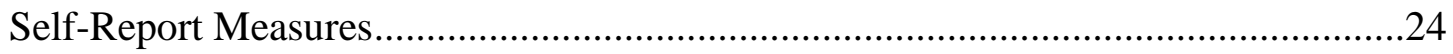

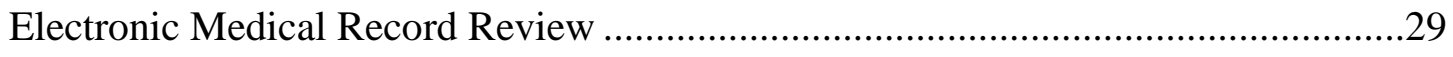

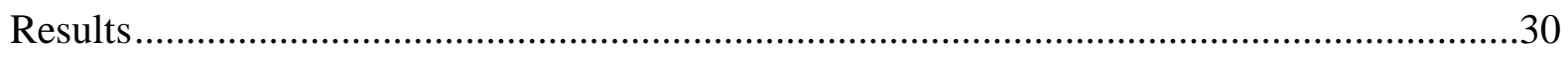

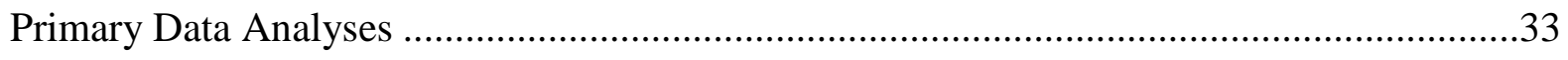

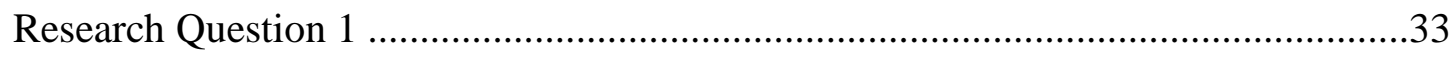

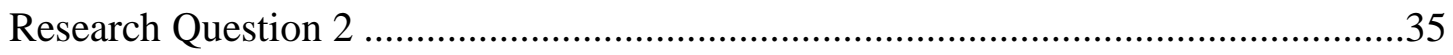




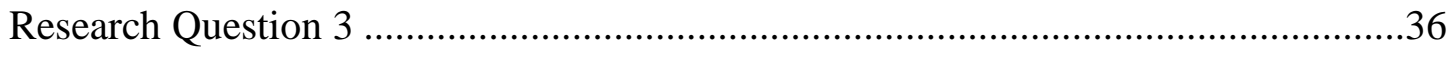

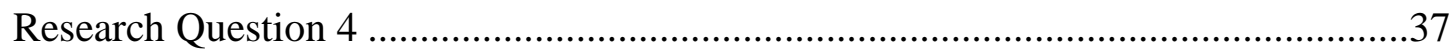

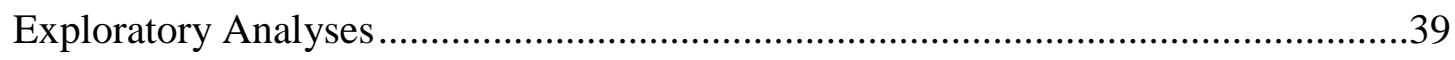

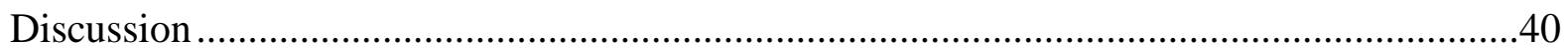

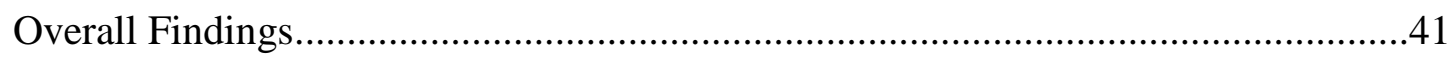

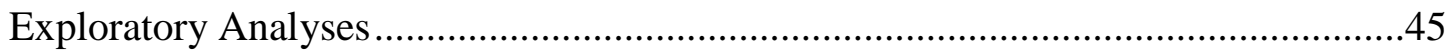

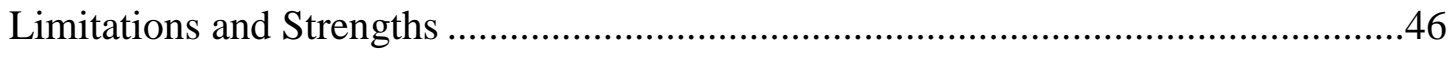

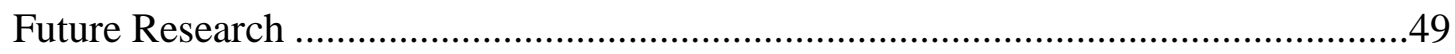

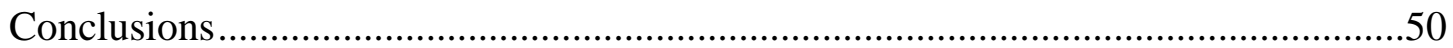

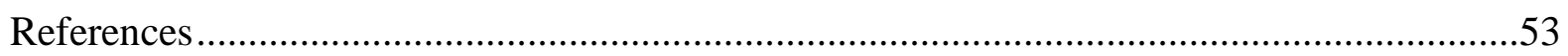

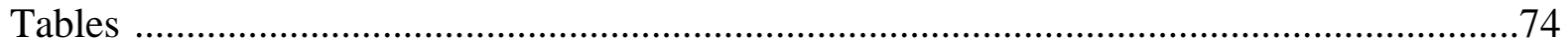

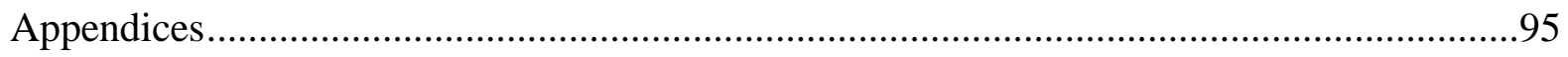




\section{Predicting Opioid Prescribing Behaviors: \\ Influence of an Expert Opioid-Risk Evaluation}

Treatments for chronic pain include a variety of pharmacological and nonpharmacological options, with opioid analgesics being a common treatment option (Turk et al., 2011). The evidence for opioid analgesics supports short-term usage; however, long-term opioid therapy has mixed results with some research indicating minimal pain reduction, and little to no evidence for improvement in functioning (Furlan et al., 2006). Other treatments that are effective in alleviating chronic pain include pharmacological, rehabilitative, medical, and psychological treatment options, with surgical options being a less effective solution (Turk et al., 2011). While opioid analgesics commonly are used in the treatment of chronic pain, there has been an increase in misuse and abuse, as well as opioid-related overdose deaths across the United States (Substance Abuse and Mental Health Services Administration, 2007; Warner et al., 2009). Physicians are in a difficult position attempting to provide chronic pain patients with the best possible care, while assessing patients for potential substance abuse and other issues. Additionally, physicians report feeling unprepared to assess for substance abuse issues and express concern over potential litigation for inappropriate prescribing of opioids (Matthias et al., 2010; Richeimer, 2005). With chronic pain becoming one of the most common reasons patients present for care (Cherry, Burt, \& Woodell, 2003), it is essential for physicians to understand the nature and treatment of this condition.

\section{Conceptualization of Chronic Pain}

Chronic pain is defined as "pain which has persisted beyond normal tissue healing time," which typically requires persistence of at least three months (International Association for the Study of Pain, 1986). This definition does not account for the quality, type, and severity of such 
pain, which limits its utility, both clinically and in research. Purves et al., (1998) proposed a more comprehensive description, suggesting chronic pain be defined as "current continuous or intermittent pain or discomfort which has persisted for more than three months, with recent or frequent seeking of treatment or use of analgesic medication." While this definition is not without flaws, it provides greater differentiation between those with acute and chronic pain. By identifying patients with chronic pain, health care professionals are better able to make treatment decisions and assess patients' progress over time.

Chronic pain is the most common reason patients seek medical services (Cherry, Burt, \& Woodell, 2003); however, estimates of prevalence vary greatly from study to study, with rates as low as $7.6 \%$ and as high as $45 \%$, with a median of 15\% (Bowsher, Rigge, \& Sopp, 1991; Brattberg, Thorslund, \& Wikman, 1989; Croft, Rigby, Boswell, Schollum, \& Sillman, 1993; Crook \& Browne, 1984; James, Large, Bushnell, \& Wells, 1991; Smith, Read, Grimshaw, Watt, \& Chambers, 1996; Von Korff, Dworkin, \& Le Resche, 1990; Verhaak, Kerssens, Dekker, Sorbi, \& Bensing, 1998). Hardt, Jacobsen, Goldberg, Nickel, and Buchwald (2008) examined data from 10,291 respondents to the National Health and Nutrition Examination Survey, finding chronic pain estimates were $10.1 \%$ for back pain, $7.1 \%$ for pain in the legs/feet, $4.1 \%$ for pain in the arms/hands, and 3.5\% for headache. Chronic regional pain accounted for $11.0 \%$ of the sample and chronic widespread pain, 3.6\%. As found in other studies (Bassols, Bosch, Campillo, Canellas, \& Banos, 1999; Bowser et al., 1991; James, Large, Bushnell, \& Wells, 1991; Von Korff, Dworkin, Le Resche, \& Kruger, 1988), women had higher rates than men for headache, abdominal pain, and chronic widespread pain. While up to $45 \%$ of the population may suffer from chronic pain, health services utilization suggests that between $10-15 \%$ of the population suffers from clinical chronic pain (i.e., chronic pain that has been diagnosed 
clinically; Smith, Hopton, \& Chambers, 1999). Thus, the majority of individuals reporting issues with chronic pain may not be seeking medical services.

Chronic pain patients who are seeking health care services are managed through specialist pain clinics, medical specialties (e.g., orthopedics), and a vast majority through primary care (Clinical Standards Advisory Group; Crombie \& Davies, 1998; Sullivan, Turner, \& Romano, 1991). One study mailed a survey to primary care providers in eight community clinics and found that $37.5 \%$ of adult appointments in a typical week involved patients with chronic pain complaints (Upshur, Luckmann, \& Savageau, 2006). Twenty percent of chronic pain patients presenting to primary care have pain due to malignancy; however, of the non-malignant chronic pain patients approximately $50 \%$ have limb and joint pain and approximately $33 \%$ present with back pain (Bowsher et al., 1991; Brattberg et al., 1989; Smith, Hopton, \& Chambers, 1999). Treatment of chronic pain often is complicated by multiple factors that contribute to the clinical presentation. General physical health and psychological (e.g., depression) and psychosocial factors are associated with chronic pain symptoms (Arnow et al., 2009; Bair, Wu, Damush, Sutherland, Kroenke, 2008; Haley, Turner, \& Romano, 1985; McCracken, Gross, Aikens, \& Carnrike, 1996; Spitzer, LeBlanc, \& Debuis, 1987). Because of these multiple contributors, there are several different treatment options that have demonstrated effectiveness in alleviating chronic pain, including pharmacological, medical, psychological, and other interventions. For further information on non-opioid treatments for chronic pain see Appendix A.

\section{Opioid Treatment for Chronic Pain}

Opioids are pain relieving medications, which bind to opioid receptors found in the brain, spinal cord, gastrointestinal tract, and other organs in the body (National Institute on Drug Abuse, 2011). After binding, they act to reduce the perception of pain, decrease the reaction to 
pain, and increase pain tolerance (National Institute on Drug Abuse, 2011). Furlan, Sandoval, Mailis-Gagnon, and Tunks (2006) evaluated 41 randomized controlled trials in a meta-analysis to determine the effectiveness of opioids for the treatment of various chronic pain conditions, including osteoarthritis, diabetic neuropathy, low-back pain, and rheumatoid arthritis. The authors concluded that opioids are capable of small reductions in pain severity and functional improvement as compared to placebo; however, when compared to other analgesic medications, they have similar reduction in pain, but less improvement in function. Trescot and colleagues (2008) found weak evidence for the use of morphine and transdermal fentanyl for long-term opioid therapy of six months or longer in managing chronic non-cancer pain; however, they concluded there was limited evidence for all other controlled substances, including the most commonly used drugs, oxycodone and hydrocodone. Therefore, there was not enough evidence to determine that other controlled substances should or should not be used for long-term opioid therapy. Two other systematic reviews concluded that due to the paucity of research on the effectiveness of long-term opioid therapy, opioids should be used infrequently and when prescribed only should be used for short-term pain relief (Manchikanti, 2004; Neush, Rutjes, Husni, Welch, \& Juni, 2009). Guidelines from two major pain associations (i.e., Neuropathic Pain Special Interest Group of the International Association for the Study of Pain; European Federation of Neurological Societies Task Force) recommend that opioids be reserved for the second- or third-line of treatment in pain problems, but can be utilized as a first-line treatment for episodic exacerbation of severe neuropathic pain (Attal et al., 2010; Dworkin et al., 2010). While the long-term use of opioids is not supported by the current literature on chronic pain, opioids remain the most potent analgesics available, and continue to be utilized for pain management (Furlan et al., 2006). 


\section{Prevalence of Prescription Opioid Abuse in the U.S.}

In recent years, the overall utilization of pharmaceuticals in the United States has greatly increased with the average of all states up to 11.5 annual prescriptions per capita (IMS Health, 2012). This general increase includes controlled substances which have averaged a $7 \%$ increase from 2010 to 2011. A growing public health concern is the abuse, dependence, and misuse of prescription pain relievers in the United States. The National Survey on Drug Use and Health (2007) reported that 12.5 million Americans used prescription pain relievers for nonmedical purposes, an increase of 1.5 million from 2002. Approximately $70.2 \%$ of individuals who abuse prescription opioids obtain the pills from friends or relatives by stealing, buying, or getting the medication for free. Of these recreational users, $81.7 \%$ indicated that the opioids originated with a prescription (Substance Abuse and Mental Health Services Administration, 2008).

Surprisingly, based on a 2009 survey of teenagers' access to substances, prescription drugs reportedly are easier to obtain than beer (The National Center on Addiction and Substance Abuse at Columbia University, 2009). In addition to the increase in opioid misuse, the number of patients admitted to substance abuse treatment facilities for nonheroin opiates and opioid abuse increased four-fold from 23,000 to more than 90,000 from 1999 to 2007 (Substance Abuse and Mental Health Services Administration, 2007). With significant increases in opioid prescriptions and opioid misuse, there also has been a rise in prescription opioid overdoses. The Centers for Disease Control and Prevention reported that 4,000 people died from opioid overdoses in 1999. This number has more than tripled with nearly 15,000 people dying from opioid overdoses in 2008 (Warner, Chen, \& Makuc, 2009).

Opioid misuse is a common problem across the United States, with special concern in West Virginia. In a state by state comparison conducted in 2011, WV ranks eighth in overall 
prescription of controlled substances, with Monongalia county ranking among the highest counties in WV (IMS Health, 2012). After dissecting opioid prescribing by specialty in WV, family medicine ranked the highest with approximately 1,000 prescriptions in 2011 with the second highest being internal medicine at approximately 600 prescriptions (IMS Health, 2012). The Centers for Disease Control and Prevention reported that WV was ranked second in the U.S. for overall opioid drug overdose deaths after examining data from 1999-2008 (Center for Disease Control and Prevention, 2011b). These statistics indicate that opioid misuse is an increasing problem across WV and the United States.

Cost of pain. When calculating the cost of pain to society, micro factors have to be extrapolated to the macro level. Understanding the required medical treatment, complications for other health problems, and decreased worker productivity is necessary to estimate the national costs. Gaskin and Richards (2012) utilized the 2008 Medical Expenditure Panel Survey to estimate cost of pain in the United States. Pain problems included both acute and chronic pain issues. The authors found that pain costs range from $\$ 560$ to $\$ 635$ billion which is larger than the annual costs of heart disease ( $\$ 309$ billion), cancer ( $\$ 243$ billion), and diabetes $(\$ 188$ billion). Interestingly, individuals with pain average an additional $\$ 261$ to $\$ 300$ each compared to individuals without pain. These estimates included health care costs attributed to pain and lower work productivity due to pain. Birnbaum and colleagues (2011) specified their research to the costs associated with prescription opioid abuse finding estimates close to $\$ 55.7$ billion in 2007, an increase of \$2.3 billion from estimates a year earlier (Hansen, Oster, Edelsberg, Woody, \& Sullivan, 2011). This estimate consists of workplace costs accounting for $\$ 25.6$ billion (46\%), health care costs for $\$ 25.0$ billion (45\%), and criminal justice costs for $\$ 5.1$ billion (9\%). With 
opioid prescribing and misuse continuing to rise, the cost of pain to society stands to increase as well.

\section{Influence of Policy on the Healthcare System and Opioid Prescribing}

In an attempt to slow the growth of opioid abuse, 34 states have initiated prescription drug monitoring programs to identify drug abuse and diversion (Drug Enforcement Administration Office of Diversion Control, 2011). Diversion includes using prescriptions for recreational purposes, sharing or selling prescriptions with family members or friends, and any other use not intended when prescribed (Gilson, Ryan, Joranson, \& Dahl, 2004). In 2011, the White House Office of National Drug Control Policy released a Prescription Drug Abuse Prevention Plan focusing on education, monitoring, proper disposal, and enforcement to reduce prescription drug abuse. First, education is aimed at increasing awareness about the dangers of prescription drug abuse and information about how to properly dispense, store, and dispose of controlled substance medications. Second, increased monitoring includes the use of prescription drug monitoring programs and requiring patients to obtain controlled substances from one provider. Third, developing and implementing consumer-friendly and environmentallyresponsible disposal programs aims to decrease "left-over" opioids from being misused. Lastly, providing law enforcement agencies with the means necessary to prevent physicians from overprescribing and stop drug seeking patients from "doctor shopping" (White House Prescription Drug Abuse Prevention Plan, 2011). These nationwide changes are meant to decrease opioid drug abuse and reduce overdose deaths.

As of July 2012, WV practitioners are required to conduct an initial search of the "West Virginia Controlled Substances Monitoring Program database for information regarding specific patients for whom they are providing pain-relieving controlled substances as part of a course of 
treatment for chronic, nonmalignant pain but who are not suffering from a terminal illness" (West Virginia Code, 2012). The information obtained from this search must be documented in the patient's medical record. Additionally, the mandate requires annual checks for these patients, with continued monitoring and documentation. Additionally, the Food and Drug Administration recently has required opioid manufacturers to develop a Risk Evaluation and Mitigation Strategy to manage potentially risky prescription drugs and ensure that the benefits of such drugs outweigh the risks (Food and Drug Administration Department of Health and Human Services, 2008). By establishing these policies, the transaction costs for the patient increase. Transaction costs are applied to economic models and the healthcare system referring to buying and selling, but also to interpersonal and system interactions (Coase, 1937; Rice, 1998; Stiles, Mick, \& Wise, 2001). More specifically, the frequency, specificity, uncertainty, limited rationality, and opportunistic behavior associated with various interactions. In this situation, the transaction costs refers to the increase in barriers (i.e., "costs") to obtaining opioids by the patient and prescribing these medications long-term for the physician. By increasing the transaction costs for patients, it may result in a decrease in patients that misuse or abuse opioids presenting to clinics with more regulations and guidelines as it would be too difficult to obtain a prescription. The purpose of these mandates is to decrease opioid abuse, lessen the costs on the health care system, and decrease inappropriate prescribing of opioids; however, it may lead to indirect harm of patients.

With greater attention on decreasing opioid misuse, legislation and policy may act to increase physicians' fear of prescribing opioids (i.e., opiophobia) and inadvertently punish patients who are using their medications appropriately. Opiophobia is described as the fear that appropriate opioid use will lead patients to become addicted to the medication, which results in a failure to prescribe opioids due to the overestimation of risks, and therefore potentially under- 
treating a patient's pain (Bennett \& Carr, 2002; Morgan, 1985; Nathan, 2008). Physicians are asked to determine if patients are malingering about their pain, a question, which many physicians have reported, they are not adequately trained to assess (Richeimer, 2005). As a result, they may avoid prescribing opioids in order to circumvent potential litigation. Medication issues (e.g., inappropriate prescribing, over-prescribing, under-prescribing) are listed as one of the top ten reasons why physicians are sued (Nathan, 2008). With the addition of stringent policy, the possibility for litigation increases and many physicians may feel the potential risks of prescribing opioids outweigh the benefits. Physician opiophobia may decrease inappropriate opioid prescribing at the cost of harming the patients who are using opioids appropriately and are benefiting from the medication.

Furthermore, the relationship between physicians and chronic pain patients can be conflictual and complicated. Physicians may feel pressured to treat the pain with opioids, have difficulty evaluating the veracity of the patients' reports of pain, and worry about diversion of opioids and misuse or abuse (Matthias et al., 2010). Additionally, because of the chronic and complicated nature of chronic pain, physicians report feeling frustrated, overwhelmed, and/or ungratified, when discussing care for patients with chronic pain (Matthias et al., 2010). Alternatively, chronic pain patients report a strong desire to be believed by their physician, citing a label or diagnosis as a confirmation of their chronic pain experience (Clarke \& Iphofen, 2005). Thus, with physicians required to question the veracity of a patient's pain report and the patient seeking confirmation of their pain experience, conflictual encounters are likely to occur. As a result of the complicated and conflictual relationship, clinical care is negatively affected with patients on chronic opioid therapy having a significantly lower incidence of receiving preventive services, specifically cervical and colorectal cancer screenings (Buckley, Calvert, Lapidus, \& 
Morris, 2010). Caring for patients with chronic pain on chronic opioid therapy is time-

consuming. Due to the high rate of opioid misuse, physicians often approach these patients with a more critical perspective and are required to question the patient's medication behaviors to ensure appropriate usage (Bendtsen, Hensing, Ebeling, \& Schedin, 1999; Bertakis, Azari, \& Callahan, 2003). This type of patient-clinician relationship may contribute to the increased likelihood of those on chronic opioid therapy discontinuing care at a clinic, initiated by either themselves or the clinic (Buckley et al., 2010). By requiring physicians to further question patients on chronic opioid therapy and approach patients with distrust, the patient-clinician relationship endures more strain and potential for conflict.

\section{Need for Evaluations to Determine Appropriateness}

A potential means to ameliorate the conflictual relationship between physicians and patients on chronic opioid therapy is by engaging other professionals in the health care team (e.g., psychologist, social worker). A pain consultant has the ability to provide an expert assessment of the patient's type, quality, intensity, and severity of pain as well as providing treatment recommendations tailored to the patient's pain problem. Additionally, a pain consultant and their evaluation can provide the physician with a means to raise concerns and discuss difficult topics about the patient's treatment and behavior without damaging the relationship. This approach allows the physician to maintain rapport with a patient and continue to provide care in a potentially difficult situation by referring to a third party source of information (i.e., pain consultant), rather than having the patient place blame on the physician which may lead to feelings of distrust and resentment. Furthermore, the use of an opioid-risk evaluation provides physicians with potential risk and protective factors to consider prior to 
prescribing an opioid, easing the decision making process and offering potential protection against litigation.

Factors related to potential opioid misuse. Research on patient characteristics associated with opioid misuse suggests there are several factors that are important to consider prior to prescribing. The American Pain Society and American Academy of Pain Medicine released Clinical Guidelines in 2009 for the use of chronic opioid therapy in patients with chronic noncancer pain. It was recommended that patient history, physical examination, assessment of the patient's family history, psychosocial factors, personal and familial history of substance abuse, patient age, and psychiatric comorbidities be evaluated prior to prescribing chronic opioid therapy (Chou, 2009).

Pergolizzi and colleagues (2012) support these criteria and recommend continued monitoring and assessment of these characteristics over the course of treatment as well as monitoring of aberrant drug taking behaviors. Continued monitoring and assessment is recommended because of the dynamic nature of the criteria (e.g., emergence of mental health condition, unemployment, divorce), thus the potential for risk status to change overtime. Aberrant drug taking behaviors have been placed in four general categories: prescription requests (e.g., early refill requests, lost pills, visits to the emergency room to obtain opioids), use of medication for non-prescribed purposes (e.g., illicit drug use, using opioids to treat anxiety or depression symptoms), illegal behaviors (e.g., stealing drugs, selling prescription drugs), and other signs or behaviors (e.g., multiple dose escalations without prior authorization, concurrent use of alcohol, hoarding drugs; Pergolizzi, 2012). All of these criteria have been found to be potential signs of current or future opioid misuse among chronic pain patients (Breitbart et al., 1997; Passik, Messina, Golsorkhi, \& Xie, 2010; Portenoy, 1996; Turk, Swanson, \& Gatchel, 
2008; Weaver \& Schnoll, 2002; Ziegler, 2005). Physicians are encouraged to utilize drugscreening tests and patient self-report to assess for aberrant behaviors; however, patients who are misusing medication are not likely to report this information to the physician. Additionally, all clinicians treating chronic pain patients with opioids should recognize that all patients are at some degree of risk because of the evidence that simply taking opioids is a risk factor for misuse and abuse (Edlund, Sullivan, Steffick, Harris, \& Wells, 2007; Jamison, Kaufmann, \& Katz, 2000). Rice and colleagues (2012) proposed a model to identify patients at risk for prescription opioid abuse, dependence, and misuse. They found that the following characteristics were most predictive of abuse: male gender, prior opioid prescriptions, at least one prior prescription of buprenorphine or methadone, at least one diagnosis of non-opioid drug abuse, mental illness, hepatitis, or having a family member diagnosed with opioid abuse. While the assessment and monitoring of risk factors is an important consideration when treating chronic pain patients on long-term opioid therapy, it does not have to prevent the prescription of opioids. Research suggests that even patients with an active opioid addiction may be successfully treated with opioids; however, it requires closely monitored conditions, which may require more care than a physician is able to provide (Weaver \& Schnoll, 2002).

\section{Medication Prescribing Decisions and Behaviors}

The research examining prescribing behaviors and decision-making has focused on factors that influence physician's decision making process, how patient characteristics (e.g., race, ethnicity) may influence prescribing, and physician characteristics and training. Nair, Manchanda, and Bhatia (2010) found that physician prescribing behavior is significantly influenced by the behavior of research-active specialists in the physician's reference group. Therefore, physicians are more likely to model their prescribing behavior after a respected 
specialist that is known to them. In a study examining physicians' opioid knowledge, beliefs, attitudes and prescribing practices, the authors found that physicians held many misconceptions about the prescribing of opioids (e.g., appropriateness of prescribing opioids for chronic pain, characteristics of addiction) and reported that fear of investigation led them to lower the dose prescribed, limit the number of refills, or prescribe a Schedule III or IV rather than a Schedule II opioid (Wolfert, Gilson, Dahl, \& Cleary, 2010). This information suggests that physicians may be more likely to modify their prescribing behaviors out of fear of legal recourse rather than based on patient characteristics.

Additionally, studies have shown that ethnic and racial minorities are less likely to be prescribed opioid analgesics than white patients (Olsen, Daumit, \& Ford, 2006; Pletcher, Kertesz, Kohn, \& Gonzales, 2008; Tamayo-Sarver, Hinze, Cydulka, \& Baker, 2003). Burgess and colleagues (2008) expanded upon this research by examining race combined with patients exhibiting challenging and non-challenging behaviors, with challenging behaviors being described as the patient being aggressive about his need for stronger pain medication, asking for drugs by name, reporting that he tried his wife's prescription for Percocet, and being highly expressive about his pain and his need for relief. The authors found that physicians were more likely to prescribe a higher dose or a stronger opioid for black patients exhibiting challenging behaviors than non-challenging behaviors. Interestingly, the result was opposite for the white patients, with physicians more likely to prescribe higher doses or a stronger opioid for nonchallenging patients. Another study showed that male physicians prescribed more opioids to white patients, while female physicians prescribed more opioids to black patients (Weisse, Sorum, Sanders, \& Syat, 2001). Lastly, Hirsh, George, and Robinson (2009) demonstrated that sex, race, age, and pain expression cues accounted for significant variance in decision making 
among nurses prescribing opioids in a virtual human model. In this study, females, African Americans, older patients, and patients expressing high pain via facial expressions were more likely to be prescribed an opioid.

Several physician and practice characteristics also influence opioid prescribing, including age, knowledge about treating pain, and beliefs and attitudes about opioids. Younger age seems to be associated with more "liberal" views on prescribing opioids (e.g., favor earlier intervention for pain control, more patient control over analgesics); however, this study examined prescribing in chronic cancer pain (Cleeland, Cleeland, Dar, \& Rinehardt, 1986). This result later was found in prescribing for non-cancer chronic pain, with younger age being associated with prescribing opioids (Hutchinson, Moreland, de Williams, Weinman, \& Horne, 2007). Another study found that previous experiences with patients addicted to drugs significantly influenced opioid prescribing, with physicians being less likely to prescribe opioids for fear of contributing to abuse or dependence (Dobscha, Corson, Flores, Tansill, \& Gerrity, 2008). Additionally, physicians unwilling to prescribe opioids held stronger beliefs that prescribing would lead to patient abuse, addiction, and potential legal recourse (Nwokeji, Rascati, Brown, \& Eisenberg, 2007). Glajchen (2001) reviewed barriers to treating chronic pain finding that lack of knowledge about opioids, negative attitudes toward prescribing opioids, and inadequate pain-assessment skills resulted in decreased opioid prescribing and poor pain management. Two other studies corroborated these conclusions finding physicians were dissatisfied with their training on pain (Hutchinson et al., 2007) and opioid prescribing was determined by personal beliefs about opioids, with those with at least a moderate belief in the effectiveness of opioids being more likely to prescribe (Hutchinson et al., 2007; Nwokeji et al., 2007). Physician misconceptions and inadequate pain management training, fear of legal recourse, lack of knowledge about laws and 
regulations, and certain patient characteristics may result in decreased opioid prescribing and inadequate management of pain.

Research addressing the complex problem of opioid misuse and opioid prescribing behaviors and their implications on societal costs and health care policy is important and has the potential to be quite impactful. The long-term goal of the current project is to improve our understanding of opioid prescribing decisions made by physicians and to use that information to inform prescriber education and health care policy. Understanding the interplay of chronic pain, opioid misuse, and opioid prescribing is critical for clinicians and researchers addressing this public health problem. This project provides a more thorough conceptualization of influences on opioid prescribing decisions, and an understanding of how to better avoid opioid misuse in chronic pain patients and how best to communicate potential risk and need to physicians.

\section{Statement of the Problem}

More thorough investigation of opioid prescribing behaviors could prove important for a numbers of reasons. First, prescription overdose deaths have seen a dramatic increase over the past 15 years, eclipsing both cocaine and heroin overdose deaths (Center for Disease Control and Prevention, 2011a). This increase is in part due to misguided views of prescription medication as being "safe" by the public; however, as overdose deaths have increased so have the number of prescriptions written by physicians (Center for Disease Control and Prevention, 2011c). With the high stress associated with patient care, physicians may not have the time or resources to adequately assess patients prior to prescribing (Matthias, 2010). As a result, physicians may under- or over-prescribe opioid analgesics resulting in inadequate management of pain. With an increased understanding of opioid prescribing decisions, overprescribing or incorrect prescribing, which can lead to overdose deaths, could potentially be reduced. Thereby, improving patient 
care and providing individuals with the most appropriate treatment interventions for their specific condition.

Second, physicians often lack training in discerning substance abuse or drug diversion (i.e., the use of prescription drugs for recreational or non-prescribed purposes) in patients and report feeling unprepared to coordinate care for patients with substance abuse and/or other psychological problems (Glajchen, 2001; Richeimer, 2005). A logical solution seems to be to provide physicians with an expert pain psychologist's assessment of the patient's potential for use and misuse; however, this solution has not been evaluated in the literature. If successful, an expert opioid-risk evaluation may alleviate some of the strain on the physician-patient relationship by improving physician knowledge of their individual patient. Additionally, when a patient needs to be denied opioid analgesics for chronic pain, the physician can utilize the consultant's evaluation as a means to avoid blame, and attempt to maintain the patient-physician relationship, while providing alternative treatments.

Third, better understanding of how specific variables influence opioid prescribing in regard to opioids, especially an expert opioid-risk evaluation, will inform the protocol for prescribing controlled substances and have implications for larger health care policies. Factors that significantly influence physician prescribing of opioids could be targets of efforts to reform policy, such as including more psychologists in the medical setting and increasing coverage of mental health evaluations and interventions by insurance companies.

Previous research has demonstrated that physician qualities (e.g., beliefs about opioids for treating chronic pain) and patient characteristics (e.g., ethnicity/race) influence prescribing behaviors (Glajchen, 2001; Hutchinson et al., 2007; Nwokeji et al., 2007; Olsen et al., 2006; Pletcher et al., 2008; Tamayo-Sarver, 2003; Wolfert et al., 2010). Moreover, it seems to be 
affected by “opinion leaders" or specialists in the physician's reference group, with physicians being more likely to imitate the prescribing behavior of specialist physicians (Nair et al., 2010). Knowing that physicians are more likely to follow the opinion of a specialist physician suggests that they may modify their prescribing behavior when presented with a psychologist's expert assessment; however, this scenario has not been addressed in the literature. Additionally, there is a limited literature addressing how factors outside of the physician influence opioid prescribing behaviors and how patient factors guide physicians' script writing. Establishing these associations is a critical step in understanding the complex nature of physician prescribing behavior and will afford a more thorough understanding of potential means to decrease overprescribing and improve patient care.

The effect of opioid prescribing decisions on patients and the larger issue of public health substantiate the importance of further examination. Although there is research that has examined physician characteristics that influence prescribing, there are few studies that explicitly target opioid prescribing and factors outside of the physician. Consequently, a crucial need in this area is the investigation of opioid prescribing behaviors. The present study is designed to determine if the results of an independent opioid risk evaluation influence prescribing decisions and to further explore other variables, outside of the physician, that may impact prescribing decisions.

\section{Research Questions}

The current study was largely exploratory in nature as there has not been an examination of the influence of an opioid risk evaluation on opioid prescribing behavior. As such, a priori hypotheses are not appropriate. The current investigation of the influence of opioid risk-status and patient characteristics on opioid prescribing behavior had four major research questions: 
1. Were patients who were prescribed opioids at the first appointment following the opioid risk evaluation different from those who were not prescribed an opioid? The groups may differ on the self-report measures, with the former group having lower scores than the latter on the Pain Catastrophizing Scale, Screener and Opioid Assessment for Patients with Pain-Revised, Pain Disability Index and Beck Depression Inventory-II. Additionally, patients may differ on demographic variables, such as level of education.

2. Did the patient's opioid risk status affect whether a physician prescribed an opioid at the first appointment following the evaluation? Each patient was ascribed a risk level (i.e., low, low-moderate, moderate, moderate-high, or high risk) following the risk evaluation. The physician may use this information when prescribing an opioid, and potentially, those ascribed a higher risk category are less likely to be prescribed an opioid.

3. What other variables influenced physician opioid prescribing behavior? Based on the literature, history of substance abuse, family history of substance abuse, cigarette smoking, mental illness, and being male are associated with opioid misuse. Examination of these variables as they relate to predicting physician prescribing behavior may provide valuable information.

4. How did the inclusion of opioid risk status and other significant variables (as determined in research question three) affect whether a physician prescribed an opioid at the first appointment following the opioid risk evaluation? Analyses resulted in a comprehensive model of variables predicting physician prescribing behaviors. 


\section{Methods}

\section{Study Design}

Between October, 2010 and March, 2013 chronic pain patients requesting or being considered for opioid pain medication presenting to the West Virginia University Department of Family Medicine clinic were referred to the Family Medicine psychology team for an opioid risk evaluation. Attending physicians are expected to refer patients for opioid risk evaluations, while resident physicians are required to refer their patients upon presentation for chronic opioid therapy. The patients had a chronic pain condition diagnosed by their primary care physician prior to the evaluation; however, the duration of the chronic pain varies across patients, all meeting the minimum requirement of lasting longer than three to six months. These patients were asked to participate in a clinical interview and to complete a number of self-report measures (described below) to assess for potential psychopathology, current functioning with pain, and potential for opioid abuse or misuse. The present study, utilizing a retrospective cohort design, followed up on the outcome of those opioid risk evaluations by way of electronic medical record review. Opioid risk status, whether or not the patient was prescribed an opioid, various demographic factors, and pain condition were abstracted from electronic medical records for each patient. Physician's decision to prescribe or not prescribe an opioid analgesic was compared across patients with varying levels of opioid risk status and a predictive model was developed to better explain the factors which may be influencing a physician's decision to prescribe.

\section{Participants}

Participants were adult (age $\geq 18$ years at the time of the evaluation) patients who reported to the West Virginia University Department of Family Medicine clinic for an opioid risk 
evaluation conducted by a psychologist or psychology trainee. The patients were referred to the Family Medicine psychologists because he or she was being considered for opioid therapy for a chronic pain condition. As outlined by the Family Medicine Clinic policy, prior to prescribing long-term opioids, the resident physicians at the Family Medicine clinic are required to refer patients for an opioid risk evaluation and the attending physicians are expected to refer patients. (See Appendix B for additional information on the Family Medicine procedure). These evaluations were conducted by one of the following individuals: faculty/licensed psychologist, postdoctoral psychologist, predoctoral intern, clinical or counseling psychology graduate student. All unlicensed psychologists, interns, or graduate students were supervised by a licensed psychologist who directly observed either in the room or via a video camera viewing system. At the time of the patient's visit, he or she completed a number of self-report instruments related to pain quality, intensity, and duration, functioning affected by pain, negative cognitions about pain, fear of activity and movement, risk for future misuse of opioids, current behaviors indicating medication misuse, and mood, in addition to a short demographic questionnaire. The patients also participated in a clinical interview conducted by a psychologist or trainee to better understand his/her pain triggers, goals for pain and function, impact of pain on functioning, pain treatment history, social and family history, and personal and familial substance abuse history. Initially, electronic record reviews were conducted on 158 patients; however, seven cases were excluded due to having two opioid risk evaluations in their record; therefore the evaluation that took place at a later date was removed and the first evaluation chronologically was utilized in the study. Opioid risk evaluations included in this sample totaled 151 (59\% female) patients. Based on guidelines established by Hosmer and Lemeshow (2000), a minimum number of 10 cases per independent variable are recommended for conducting a logistic regression, with a 
preferred case-to-variable ratio of 20 to 1 . By including 151 patients, the analyses can include between 7-15 independent variables in the final predictive model. These patients were further categorized based on their opioid risk status with $36(23.8 \%)$ recorded as low risk, $14(9.3 \%)$ as low-moderate risk, $39(25.8 \%)$ as moderate risk, $19(12.6 \%)$ as moderate-high risk, and 43 $(28.5 \%)$ as high risk. Due to unequal sample size in each category resulting in small cell sizes for analyses, the low and low-moderate group was combined and the moderate and moderatehigh group was combined. These changes resulted in the following categories: 50 (33.1\%) recorded as low/low-moderate risk, $58(38.4 \%)$ as moderate/moderate-high risk, and $43(28.5 \%)$ as high risk. See Tables 1 and 2 for information about referrals, risk status, and evaluations. Of note, it may appear when examining Table 2 that there are differences in the assigned risk status and the psychologist/trainee; however, these potential differences seem to be related to the scheduling process and characteristics of the psychologist/trainee.

Generally speaking, participants of the project were residents of Morgantown and surrounding areas of West Virginia and Pennsylvania and represent the ethnic and racial makeup of the Appalachian area. For this study, $96.7 \%$ of the sample reported their race/ethnicity as "white/Caucasian" and 3.3\% reported "black/African American." The mean age of the sample was 48.2 years $(S D=11.1)$, with patients ranging from 19 to 80 years old. The sample consisted of 89 females $(58.9 \%)$ and 62 males $(41.1 \%)$. The education level of participants was as follows: $11^{\text {th }}$ grade and below $(29,19.2 \%)$, high school graduate or GED $(65,43.0 \%)$, Associate's degree or some college (30, 19.9\%), and Bachelor's degree or higher $(17,11.3 \%)$.

\section{Opioid Risk Evaluation}

Patients participating in the opioid risk evaluation typically were new chronic pain patients attempting to establish care at the Family Medicine clinic; however, any individual 
attempting to or being considered for long term opioid treatment can be referred for an evaluation. The resident physicians at the clinic are required by department policies to refer their patients and the attending physicians are expected to refer their patients, but may not follow this guideline unless they have a concern about the patient (e.g., psychological problem, substance abuse). Additionally, patients presenting with obvious high risk indicators (e.g., active substance abuse or opioid misuse) may not be referred for an opioid risk evaluation and instead may be rejected for opioid consideration by the physician before beginning the evaluative process. As previously described, the patient meets with a psychologist or psychology trainee for a clinical interview which addresses his/her pain triggers, goals for pain and function, impact of pain on functioning, pain treatment history, social and family history, and personal and familial substance abuse history. After this interview, the trainee and supervisor thoroughly discuss the case and identify any potential problem areas based on information in the literature. If a trainee was not involved, the licensed psychologist identifies problem areas independently. These potential problem areas include: history of substance abuse, family history of substance abuse, psychopathology, alliance with provider, history of compliance, lifestyle stability, willingness to pursue pain management options other than opioids, and mental health problems.

After discussing the patient, reviewing the patient's medical record, and interpreting their self-report measures, a risk status is ascribed to the patient. This risk status is based on the number and severity of each potential problem area, which then is interpreted into one of the following risk categories: low, low-moderate, moderate, moderate-high, or high, as previously described. Certain factors may be weighted more heavily due to the abundance of research regarding the risk of opioid abuse and said factor. For example, if a patient has an extensive history of substance abuse with numerous failed sobriety attempts or no sobriety attempts, this 
patient likely would be considered high risk. Other factors that likely indicate high risk include current substance abuse, and evidence of diversion or medication misuse/abuse.

Next, a report is generated which outlines the presenting problem, medical/psychological history, current medications, history of pain problem, relevant psychosocial history, current status and functioning, mental status, standardized testing (i.e., McGill Pain Questionnaire, Pain Disability Index, Tampa Scale for Kinesiophobia, Beck Depression Inventory-II, Screener and Opioid Assessment for Patients), diagnostic impressions, and lastly the conclusions and recommendations. The conclusions and recommendations section outlines the patients risk status for misuse of opioid pain medications, presents positive indicators and cautions, and specific treatment options that may be helpful for the patient, which may or may not include a recommendation for opioid analgesics. This report is included in the patient's medical record and is not considered a protected document as most psychiatry notes. The purpose is for this information to be accessible to the physicians managing the patient's pain problem. Because this report is not protected beyond the strict standard of access to the medical record system, the writer of the report will not include detailed information about potentially sensitive topics, such as sexual abuse. Instead the writer may indicate that the patient experienced abuse, and report more specific information directly to the physician, if it seems necessary for treatment. This safeguard is in place to protect the patient's privacy and maintain confidentiality.

Considering the prescribing of opioid analgesics, it is important to note that the West Virginia University Department of Family Medicine has policies in place which have evolved over the course of the past few years. The requirement of opioid risk evaluations prior to prescribing was established in Fall 2010 and additional guidelines were added, including a check of the Board of Pharmacy for the patient, urine drug screens prior to prescribing and periodically 
thereafter, and an approximate 30 day waiting period before physicians are allowed to prescribed analgesic narcotics to patients. Of note, no other study has been conducted in a setting with this type of system-level protocol in place. Therefore, it is unclear how such a protocol may affect the outcome of this investigation; however, its impact may be such that there is a decrease of high risk patients continuing treatment in this setting due to the "transaction costs" (Coase, 1937; Rice, 1998; Stiles, Mick, \& Wise, 2001).

\section{Self-Report Measures}

Demographic and general pain information questionnaire. The demographic form is a self-report questionnaire consisting of approximately 30 items (see Appendix C). It covers general demographic information, queries the respondent about number of times the patient has utilized the emergency department in the past year, tactics attempted to alleviate pain (e.g., yoga, physical therapy, medication) and the patients perceived degree of helpfulness, as well as caffeine, alcohol, nicotine, and other substance use. Additionally, it includes items related to previous and current psychological symptoms (e.g., loss of energy, feeling nervous, hearing voices in your head).

Short Form-McGill Pain Questionnaire. The Short Form-McGill Pain Questionnaire (SF-MPQ) is a 15-item self-report questionnaire which utilizes a four-point scale $(0=$ none to 3 $=$ severe) requiring respondents to indicate the severity of various pain descriptors (e.g., throbbing, gnawing, splitting; Melzack, 1987; see Appendix D). It consists of 11 sensory words and 4 affective words. Patients also rate their present pain intensity on a $0-5$ scale. Total score ranges from 0-45; however, this measure may be best utilized to understand the type, intensity, and affective nature of the pain as the total score does not provide quantitative cut-offs for interpretation. 
Administration time for the SF-MPQ is short, the instrument is widely used, and there is good evidence of reliability and validity. The SF-MPQ has good internal consistency reliability ( $r=0.73-0.89$; Burckhardt \& Bjelle, 1994) and demonstrates strong concurrent validity with the MPQ total score $(r=0.67-0.87$; Melzack, 1987). The SF-MPQ also has demonstrated an appropriate level of overlap ( $r=.51$ to .94 ) with other pain measurements (e.g., Long-Form McGill Pain Questionnaire, Present Pain Intensity, Visual Analogue Scale; Melzack, 1987). Test-retest reliability over one- to three-days apart ranged from 0.62 to 0.95 in samples of patients with musculoskeletal pain and rheumatic pain (Strand, Ljunggren, Bogen, Ask, \& Johnsen, 2008). The SF-MPQ is a good measure of pain quality and intensity and has demonstrated adequate reliability and validity for inclusion in the current study. Internal consistency in this study was acceptable for the SF-MPQ $(\alpha=.84)$.

Pain Disability Index. The Pain Disability Index (PDI) is a 7-item, self-report measure designed to assess the degree to which several aspects of the patient's life presently are disrupted by persistent pain (Pollard, 1984; see Appendix E). Respondents are asked to rate, on a 10-point scale $(0=$ no disability to $10=$ total disability $)$, the level of disability they experience due to persistent pain in various life activities (e.g., family and home responsibilities, recreational activities). Total scores range from 0-70; higher scores indicate greater disability.

The PDI has the following strengths: short administration time, assessment of disability level related to a broad range of life events, established norms for clinical (i.e., chronic pain) populations, and well-evidenced reliability and validity. Internal consistency was good, Cronbach's $\alpha=.86$, within a chronic low back pain sample (Pollard, 1984). Test-retest reliability over a one week interval was found to be good, ICC = .91 (Grönblad et al., 1993; Tait, Chibnall, \& Krause, 1990). Additionally, Pollard (1984) found that using the PDI allowed 
differentiation between patients with chronic low back pain who were categorized as highly or minimally disabled. For the demonstrated ability to discriminate between those with high and low disability and the adequate reliability and validity, this instrument is of value for the present study. Cronbach's alpha for the PDI in the current study was .83.

Pain Catastrophizing Scale. The Pain Catastrophizing Scale (PCS) is a 13-item selfreport measure of thoughts and feelings patients may have when in pain (Sullivan, Bishop, \& Pivik, 1995; see Appendix F). Respondents rate the degree to which they experience various thoughts and feelings on a five-point Likert-type scale from not at all to all the time. Examples of items include "I worry all the time about whether the pain will end" and "There's nothing I can do to reduce the intensity of the pain." The PCS yields a total score (0-52) and three subscale scores assessing rumination, magnification and helplessness. Higher scores indicate more negative thoughts and feelings about pain.

The PCS is relatively short, there are established norms for clinical (i.e., chronic pain) and nonclinical populations, and there is good evidence of reliability and validity. The PCS has adequate to excellent internal consistency for both the total score (Cronbach's $\alpha=.87$ ) and subscales (rumination, $\alpha=.87$; magnification, $\alpha=.66$, and helplessness, $\alpha=.78$; Sullivan et al., 1995). Test-retest reliability over a six-week period was found to be good by Sullivan et al., (1995), $r=0.75$. Studies by Osman et al., (1997 \& 2000) found additional support for the threefactor structure of the PCS and further evidence of reliability, as well as criterion-related, concurrent, and discriminant validity. For its ease of use and well-evidenced reliability and validity, the PCS is a good measure of negative cognitions associated with chronic pain for the current study. Internal consistency for the PCS in this study was acceptable $(\alpha=.94)$. 
Tampa Scale for Kinesiophobia. The Tampa Scale for Kinesiophobia (TSK) is a 17item, self-report measure designed to assess the degree to which patient's fear or worry about movement and activity (Miller, Kori, \& Todd, 1991; see Appendix G). Respondents are asked to rate, on a 4 -point scale $(1=$ strongly disagree to $4=$ strongly agree $)$, the degree to which each statement represents their feelings. Items include, “I'm afraid I might injure myself if I exercise," and "People aren't taking my medical condition seriously enough." Total scores range from 17-68; higher scores indicate greater fear of movement or activity.

Administration time for the TSK is relatively short, there are established norms for clinical (i.e., chronic pain) and nonclinical populations, and good evidence of reliability and validity. In a sample of adults with chronic back and/or neck pain, a Cronbach's alpha of 0.84 was observed, indicating a high level of internal consistency (French, France, Vigneau, French, \& Evans, 2007). Test-retest reliability of the total score has been established by SwinkelsMeewisse, Swinkels, Verbeek, Vlaeyen, and Oostendorp (2003), $r=0.78$. Convergent and discriminant validity was found to be good when compared to other measures of fear-avoidance behavior and pain catastrophizing (French et al., 2007). Additionally French and colleagues (2007) found additional support for the two-factor model originally found by Clark, Kori, and Brockel (1996) and later reaffirmed by Roelofs, Goubert, Peters, Vlaeyen, and Crombez (2004). For its ease of use and well-evidenced reliability and validity, the TSK is a good measure of fear and avoidance of movement and activity for the current study. Cronbach's alpha for the TSK in the current investigation was .81 .

Screener and Opioid Assessment for Patients with Pain-Revised. The Screener and Opioid Assessment for Patients with Pain-Revised (SOAPP-R) is a 24-item self-report measure utilized for screening risk potential for aberrant medication-related behavior among persons with 
chronic pain (Butler, Fernandez, Benoit, Budman, \& Jamison, 2008; see Appendix H).

Respondents rate the frequency they experience symptoms and events related to opioid misuse on a five-point Likert-type scale from never to very often. Examples of items include "How often do you have mood swings" and "How often have you counted pain pills to see how many are remaining." Total score ranges from $0-96$, scores $\geq 18$ indicates the patient is at risk for opioid misuse.

The SOAPP-R is widely used to assess potential for opioid abuse, there are established norms for clinical (i.e., chronic pain) and nonclinical populations, and good evidence of reliability and validity. In a sample of patients prescribed opioid medication for chronic noncancer pain, a Cronbach's alpha of 0.88 was observed, indicating adequate internal consistency and excellent test-retest reliability over one week was demonstrated, $r=.92$ (Butler et al., 2008). Convergent and discriminant validity was found to be good when compared to other measures of aberrant drug behavior and social desirability (Butler et al., 2008). The SOAPP-R provides important information about the potential for opioid misuse and demonstrates good reliability and validity; as such it is a valuable measure for this investigation. Internal consistency for the SOAPP-R in the current study was acceptable $(\alpha=.90)$.

Beck Depression Inventory-II. The Beck Depression Inventory-II (BDI-II) is a 21 item self-report questionnaire which utilizes a four-point scale $(0=$ minimal to $3=$ severe $)$ requiring respondents to indicate the severity of depressive symptoms (Beck, Steer, \& Brown, 1996). The items on the BDI-II include questions relating to hopelessness, irritability, guilt, fatigue, weight loss, and lack of interest in sex. Total score ranges from 0 to 63, with cutoff scores indicating minimal, mild, moderate, and severe depression. 
The BDI-II is widely used both clinically and in research, there are established norms for clinical (i.e., chronic pain) and nonclinical populations, and good evidence of reliability and validity. Both high internal consistency $(\alpha=.92)$ and high convergent validity have been established for the BDI-II based on Pearson correlations between the BDI-II and the depression scale of the SCL-90-R ( $r=.89$; Steer, Clark, \& Beck, 1999). Additionally, in a sample of chronic pain patients, internal consistency remained high $(\alpha=.92)$, and results supported a singular second-order latent construct with three-factor subscales (i.e., Negative Attitude, Performance Difficulty, and Somatic Elements; Harris \& D’Eon, 2008). Test-retest reliability over a oneweek period was found to be good by Sprinkle et al. (2002), $r=0.96$, which is similar to that found by Beck, Steer, and Brown (1996), $r=.93$. Because it has well-evidenced reliability and validity for both chronic pain and nonclinical samples, the BDI-II is a good measure of depression for the current study. Cronbach's alpha for the BDI-II in this study was .91. The BDI-II is not displayed in the appendices due to its copyrighted status.

\section{Electronic Medical Record Review}

Electronic medical records were available for all of the participants of the study through the West Virginia University Department of Family Medicine clinic. Information gathered from the electronic medical record was immediately entered into a database to assure complete abstraction across participants. Several variables were collected including, whether the patient was prescribed an opioid at the first appointment following the opioid risk evaluation, the prescribing physician's training level and sex, patient's primary pain condition, mental health diagnoses, history of substance abuse, family history of substance abuse, history of abuse, employment status, smoking status, education level, evaluator training level, Board of Pharmacy review, urine drug screen, as well as the patient's sex, age, ethnicity/race, and scores on the 
SOAPP-R, PCS, PCI, TSK, and BDI-II. This chart review process provided a comprehensive and standardized measure of potential factors related to being prescribed an opioid.

Access to electronic medical records was approved by the West Virginia University Department of Family Medicine dean and the appropriate faculty and administrators. Electronic medical record reviews were conducted by Alison Vargovich, under the supervision of collaborators at the Department of Family Medicine. Chart abstraction reliability was assessed via abstraction comparison for $10 \%$ of the cases across 158 participants with reliability checks conducted every 20 participants by Jeannie Sperry, Ph.D., as she was the Family Medicine supervisor at the time. Reliability was excellent across the data collection window; there were no discrepancies in the recorded outcome variables, and minimal discrepancies in all other variables collected across patients. More specifically, for all participants included in the reliability checks, 240 out of 260 variable cases, or $90.2 \%$, were congruent between the dataset and reliability check. There were 26 out of 266 variable cases with discrepancies $(9.8 \%)$, but after closer inspection only 4 out of those 26 variable cases, or $15.4 \%$, required a modification to the dataset. Prior to data collection, Alison Vargovich and Jeannie Sperry, Ph.D. were trained on the Health Insurance Portability and Accountability Act of 1996 (HIPAA) Privacy and Security Rules and had current ethics training and Collaborative Institutional Training Initiative (CITI) program certification for work with human subjects.

\section{Results}

All Statistical analyses were performed using PASW Statistics 21.0.0.0 (IBM SPSS, Chicago, IL). Variables first were examined to ensure there were no out-of-range values that were theoretically impossible based on the structure of the variable (e.g., possible questionnaire responses), and any issues addressed. 
As suggested by Menard (2010), preliminary analysis of the data was performed to check the assumptions of logistic regression with respect to the selected predictors of the study. Univariate outliers were detected by considering histograms and box plots for each variable. There were 18 individual data points detected as potential outliers across all of the variables. These outliers were further evaluated by comparing the mean to the $5 \%$ trimmed mean to determine the influence the potential outliers were having on the data (Pallant, 2010). These outliers were not determined to be significantly influencing the mean and were included in the dataset. Outliers for dichotomous variables were examined through frequencies to determine if any violated the $90 \%-10 \%$ split between groups; no variables violated this guideline (Howell, 2010). Multivariate outliers were screened by checking the data for participant leverage values greater than $2 k / N$, where $k$ equals the number of predictor variables (Tabachnick $\&$ Fidell, 2007); no variables violated the multivariate outlier guidelines.

All predictor variables were subjected to linear regression analysis to evaluate multicollinearity (Menard, 2010). Multicollinearity among predictors in logistic regression creates problems for the validity of the model for the investigation. In particular, it affects the validity of the statistical tests of the regression coefficients by inflating their standard errors (Garson, 2010). The results of the analysis showed the data did not violate the multicollinearity assumption. The collinearity statistics, specifically tolerance values and the variance inflation factor, were examined. None of the variables were below the recommended guideline of .10 for tolerance or above 10 for the variance inflation factor, suggesting that there were no problems with multicollinearity among the variables (Field, 2005; Pallant, 2010). See Table 3 for collinearity statistics. Additionally, a bivariate correlational analysis was conducted to determine high correlations among variables ( $\geq .80$; Tabachnick \& Fidell, 2007). The variables with the 
highest correlation were the total score for the SOAPP-R and BDI-II, $r=.65, p<.001$; and no variables met or exceeded the suggested guideline. See Table 4 for bivariate correlations for questionnaires.

To address missing data, multiple imputation (MI) was utilized in order to reduce errors, maintain statistical power, and retain the cases in the dataset (Osborne, 2013). The MI statistical technique has been demonstrated to be superior to mean substitution, listwise deletion, and single imputation and results in greater generalizability and replicability as it explicitly models the missingness and gives the researcher confidence intervals for estimates rather than trusting to a single imputation (Schafer, 1999; Schafer \& Graham, 2002). The MI method involves three steps, imputation, analysis, and pooling. First, the missing entries of the incomplete dataset are "filled in" or "imputed" with plausible values based on the distribution of the data derived from a combination of Bayesian theory and Monte Carlo technique. These plausible values are imputed into a designated number of datasets determined by the researcher. The suggested number is between 5 and 20 (Schafer, 1999; Schafer \& Graham, 2002), but for these analyses it was determined that 10 imputed datasets would be sufficient due to the relatively small amount of missing values. This first step results in 10 imputed datasets with plausible values replacing the missing items. The second step, analysis, refers to the planned analyses that are conducted utilizing all of the imputed datasets, which results in the final step, pooling. The output for the analyses includes statistics based on each imputed dataset, which is then combined and analyzed to provide "pooled" statistical output.

In order to utilize the MI method, it is assumed the missing data are random; however, while it is preferred to be missing at random, the MI method is resilient to various types of missingness (Little \& Rubin, 2002). Additionally, to utilize the MI method effectively, it is 
important to understand the total percentage of missing items and the percentage missing within a variable; however, the number missing within each case is irrelevant to the analyses as these values can be imputed accurately providing there is sufficient data within the variable (Schafer, 1999; Schafer \& Graham, 2002; Tabachnick \& Fidell, 2012). Due to the rigorous nature of the record review, there were minimal missing data in the variables collected from the patient's medical record (1.7\%); however, there were missing data among the self-report measures, which is what the multiple imputation was utilized to address. In the current study, missing data were analyzed for patterns through the multiple imputation analyze patterns feature of SPSS to determine missingness. There were no significant patterns identified and it was determined that the missing values were missing at random. Further assessment of the missing values within the self-report measures revealed 5.6\% missing across all of the participants in the form of items on the questionnaires. Additionally, there was $<10 \%$ missing within each measure item, which is the suggested guideline (Bennett, 2001); however, Tabachnick and Fidell (2012) indicated that the missing data mechanisms and the missing data patterns likely have greater impact on research results than the proportion of missing data. See Table 5 for the percentage of missing items for each measure.

\section{Primary Data Analyses}

\section{Research Question 1}

Were patients who were prescribed opioids at the first appointment following the opioid risk evaluation different from those who were not prescribed an opioid? Descriptive statistics (e.g., means and standard deviations) for relevant dependent and independent variables, across the entire study sample are reported in Tables 6 and 7. Additional information about differences in demographic and psychosocial variables by opioid prescribing group is in Tables 8 
and 9. Chronic pain diagnoses and mental health problems across groups are presented in Table 10. Across groups (i.e., prescribed an opioid, not prescribed an opioid) patients did not differ significantly in demographic variables, specifically age, $t(149)=-.80, p=.43$, sex, $\chi^{2}(1, \mathrm{~N}=$ $151)=.05, p=.83$, phi $=.03$, or ethnicity/race (i.e., black and white), $\chi^{2}(1, \mathrm{~N}=151)=1.70, p=$ .19, phi $=-.14$.

Further analyses, $t$-tests for continuous variables and chi-square tests for independence (with Yates Continuity Correction) for categorical variables, were conducted to investigate possible group differences across several variables, as shown in Tables 8 and 9. Variables assessed included the following: employment, relationship, and smoking status, abuse history, substance abuse, family substance abuse, education, pain diagnoses, mental health diagnoses, pain rating at the time of the appointment, duration of chronic pain, number of times married, number of children, as well as total scores for self-reported pain severity (MPQSF), pain catastrophizing (PCS), misuse or diversion behaviors (SOAPP-R), depression symptoms (BDIII), pain disability (PDI), and fear of movement (TSK). . Patients who were more likely to be prescribed an opioid included those who were married or with a long-term partner and those patients who reported higher level of education. Patients who were less likely to be prescribed an opioid included those reporting some form of abuse, a history of substance abuse, a higher pain rating at the time of the evaluation, as well as patients with higher scores on the PCS, SOAPP-R, and BDI-II.

\section{Research Question 2}

Did the patient's opioid risk status affect whether a physician prescribed an opioid at the first appointment following the evaluation? The dependent variable, opioid prescribing, was constructed as a "yes/no" dichotomous indicator of whether or not a patient was 
prescribed an opioid following an opioid risk evaluation. Patients prescribed an opioid at the first appointment following the opioid risk evaluation were coded as YES (1) and patients not prescribed an opioid or did not return following the opioid risk evaluation were coded as NO (0). The dependent variable, risk status, was coded with High $=1$, Moderate and Moderate-High $=2$, and Low and Low-Moderate $=3$. See Table 11 for the number of patients in each risk category by opioid prescribing group.

In order to examine the predictive association between opioid risk status (i.e., low/lowmoderate, moderate/moderate-high, high) and opioid prescription decision (i.e., prescribed, not prescribed), a binary logistic regression was conducted. The overall model was statistically significant, $\chi^{2}(1, \mathrm{~N}=151)=37.10, p<.001$, indicating that the model was able to distinguish between patients who were prescribed an opioid and those who were not. The model as a whole explained between 21.8\% (Cox and Snell R square) and 29.3\% (Nagelkerke R squared) of the variance in opioid prescribing, and correctly classified $72.2 \%$ of cases. The Wald statistic indicated that the risk status variable significantly predicted opioid prescribing. The unstandardized regression coefficient is positive which indicates a positive relation with the probability of "success" (i.e., when risk status decreases probability of being prescribed an opioid increases). Additionally, when the probability of being prescribed an opioid is more than the probability not being prescribed an opioid, then the odds ratio will be greater than 1 , as it is in the current analysis. Therefore, the odds of being prescribed an opioid increased 4.22 times for each level decrease in risk status. See Table 12 for more information.

\section{Research Question 3}

\section{What other variables influenced physician opioid prescribing behavior? Next, a} series of univariate logistic regressions (i.e., each analysis included one predictor variable) was 
utilized to examine potentially significant variables in predicting physician opioid prescribing to determine which factors should be included in the final model (Agresti, 2007). Based on the literature, there were 21 factors independently reviewed and considered for inclusion in analyses. These variables were: patient's sex, patient's age, substance abuse history, familial substance abuse history, mental health diagnoses, current smoking status, employment status, history of abuse, relationship status, education, pain diagnoses, Board of Pharmacy review, urine drug screen, physician training level, physician sex, as well as total scores on the SFMPQ, PCS, PDI, SOAPP-R, TSK, and BDI-II. The Board of Pharmacy review and urine drug screen variables were excluded from analyses as both variables had inadequate data for inclusion in analyses with the urine drug screen missing in $69.5 \%$ of the sample and the Board of Pharmacy review missing in $79.5 \%$ of the sample. This information was missing as it was not consistently reported in the patient's electronic medical record, which may be due to the patient not undergoing a urine drug screen or Board of Pharmacy review, or physicians not reporting this information in the medical record, as it only recently was required by West Virginia state law in July 2012 (West Virginia State Code, 2012). All 19 other variables were included in this stage of analysis. The variables that made a unique statistically significant contribution to the model at the $p<.05$ level were substance abuse history, history of abuse, relationship status, education, and total scores on the SOAPP-R, PCS, and BDI-II. Due to the number of variables significant at the 0.05 level, values at the 0.25 level were not considered as there would not be enough power to adequately assess these variables in further analyses (Bendel \& Afifi, 1977; Mickey \& Greenland, 1989). See Table 13 and 14 for pertinent information regarding these variables.

Based on the significant factors discovered in the series of univariate binary logistic regressions, a multivariate logistic regression was conducted. The variables of substance abuse 
history, history of physical abuse, relationship status, education, and total scores on the SOAPPR, PCS, and BDI-II were entered as the independent variables, and whether the physician prescribed an opioid at the first appointment following the opioid risk evaluation as the dependent variable. Risk status was not included in this analysis in order to determine the contribution of these other variables to the predictive model. After examining the overall model and variable statistics, the variables of history of abuse, education, and total scores on the SOAPP-R, PCS, and BDI-II were removed from the analyses as they did not account for a significant amount of the variance; however, substance abuse history remained statistically significant. When removing substance abuse history from the analyses, the overall model remained significant; however, none of the predictor variables were significant. Therefore, the final model included substance abuse history and risk status, but no other predictor variables. See Table 15 for additional information on the variables and model.

\section{Research Question 4}

How did the inclusion of opioid risk status and other significant variables, as

\section{determined in research question 3 , affect whether a physician prescribes an opioid at the}

first appointment following the opioid risk evaluation? To examine the unique contribution of risk status in the prediction of opioid prescribing, a hierarchical logistic regression analysis was conducted. In step one, opioid prescribing was the dependent variable, and substance abuse history was included as a control variable. Due to the lack of significance within the binary logistic regressions for age and sex, these variables were not included as control variables. In step two, the risk status variable was entered into the equation.

The results of step one indicated that the model was statistically significant $\chi^{2}(2, \mathrm{~N}=$ $151)=20.44, p<.001$, with substance abuse history being statistically significant at the $p<.001$ 
level. In step two, risk status was entered into the regression equation. The overall model was statistically significant, $\chi^{2}(2, \mathrm{~N}=151)=39.61, p<.001$, indicating that the model was able to distinguish between patients who were prescribed an opioid and patients who were not. The model as a whole explained between $23.1 \%$ (Cox and Snell R square) and 31.1\% (Nagelkerke R squared) of the variance in opioid prescribing, and correctly classified $70.9 \%$ of cases. This additional step was significant, $\chi^{2}(1, \mathrm{~N}=151)=19.17, p<.001$, indicating that the added risk status variable significantly improved the model. Wald statistics indicate that only the risk status variable was significant in the final model $(p<.001)$, and substance abuse history was no longer significant $(p=.11)$. The odds of being prescribed an opioid increased 3.40 times for each level decrease in risk status. See Table 16 for additional information.

The inclusion of substance abuse history in the model minimally reduces the percentage of correctly classified patients from $72.2 \%$ to $70.9 \%$. Additionally, when the analysis was conducted with only substance abuse history as the predictor variable, the model was significant, $\chi^{2}(1, \mathrm{~N}=151)=20.44, p<.001$, substance abuse history was significant at the $\mathrm{p}<.001$ level, and the model correctly classified $69.5 \%$ of the patients. It appears that substance abuse history parallels the predictive utility of risk status, when included independently. While these variables both significantly predict opioid prescribing independently, it was decided that the final model only should include risk status as it was the variable of interest; it remained significant when included with substance abuse history, and substance abuse history did not improve the overall model. See Table 12 for the final model.

The overall predictive utility of the final model can be found using the Receiver Operating Characteristic (ROC) curve analysis (Metz, 1978; Zweig \& Campbell, 1993) with opioid prescribing being the state variable and the predicted probabilities as the test variable. 
This test demonstrates how well the model classifies individuals and selects a "cut-off" point to maximize sensitivity and specificity. To interpret the area under the curve (AUC) statistic, an AUC of 1 represents a perfect classification and an AUC of 0.5 represents the same accuracy as chance. A general guide is that fair-to-excellent accuracy is achieved when AUC $\geq 0.7$ (i.e., .90$1=$ excellent, $.80-.90=$ good, $.70-.80=$ fair, $.60-.70=$ poor, and $.50-.60=$ inclusive/little to no utility; Hanley \& McNeil, 1982; Zou et al., 2003). The ROC curve analysis showed that the area under the ROC curve was $.76(76.3 \%$; $\mathrm{CI}=69-84 \%)$. The model is significantly better than chance, in terms of classifying whether or not a patient was prescribed an opioid, $p<.001$.

\section{Exploratory Analyses}

An area of concern was the differences between residents' and attending physicians' use of the risk status information. Due to the selection bias which exists when referring patients (i.e., residents are required, attending physicians are strongly encouraged), it was unclear how attending physicians may refer patients and if they would utilize the opioid risk evaluation in their prescribing decision. Based on the sample of 151 patients, 49 were referred by attending physicians and 102 by resident physicians. (See Tables 2 and 17 for additional information about referrals by physician training.) The 49 referrals came from 13 different attending physicians and the 102 referrals came from 27 different resident physicians. These numbers are uneven, though there are relatively equivalent numbers of resident and attending physicians on staff (i.e., 20 of each). A chi-square test for independence (with Yates Continuity Correction) was conducted to determine if there was an association between risk status and physician training level. This relationship was not significant, $\chi^{2}(2, \mathrm{~N}=151)=.69, p=.71$. Next, a binary logistic regression was conducted with opioid prescribing as the outcome variable and physician training level as the predictor variable. Neither the overall model, $\chi^{2}(1, \mathrm{~N}=151)=1.49, p=$ 
.22 , nor the Wald statistic, Wald $=1.47, p=.23$, were statistically significant. This outcome suggests that the model was not able to distinguish between patients who were prescribed an opioid and patients who were not, based on physician training level alone.

Additionally, a secondary concern involved the different levels of training within the psychology team (i.e., graduate students, predoctoral interns, postdoctoral fellows, and licensed psychologists) assigning the risk status and the potential for bias when assigning. In order to examine this concern, a chi-square test for independence (with Yates Continuity Correction) was conducted between opioid risk status (i.e., low/low-moderate, moderate/moderate-high, high) and evaluator training level (i.e., graduate students, predoctoral interns, postdoctoral fellows, licensed psychologists). There was no significant association between opioid risk status and evaluator training level, $\chi^{2}(6, N=151)=10.31, p=.12$, phi $=.26$. See Table 1 for frequencies and percentages of assigned risk status by evaluator training level. Additional analyses and examination are necessary to fully understand the role of the evaluator and the influence it has on opioid risk status and prescribing; however, it does not appear to be an issue within this sample.

\section{Discussion}

Few studies have addressed opioid prescribing behaviors beyond patient demographic attributes. Moreover, little research has addressed how psychological evaluation, and assignment of risk status, may contribute to decisions by physicians in prescribing for the treatment of chronic pain. The current study has several interesting findings regarding opioid prescribing and patient characteristics. Patients prescribed an opioid were more likely to be married or with a long term partner and have a higher level of education. Patients not prescribed an opioid were more likely to report a higher pain rating at the time of the evaluation, a history of abuse or substance abuse, or have higher total scores for pain catastrophizing (PCS), misuse or diversion 
behaviors (SOAPP-R), and depression symptoms (BDI-II). Additionally, the best predictors of opioid prescribing were substance abuse and opioid risk status, with patients with no history of substance abuse and lower risk status being more likely to be prescribed an opioid. The finding that substance abuse history is related to opioid prescribing corroborates previous study findings (e.g., Pergolizzi, 2012; Turk, Swanson, \& Gatchel, 2008); however, the influence of opioid risk status on opioid prescribing is an interesting and important finding. Interestingly, age, sex, and ethnicity/race were not significant predictors of opioid prescribing, suggesting that providing physicians with additional information about their chronic pain patient's potential for opioid abuse may act to reduce prescribing bias based on demographic factors as found in previous studies.

\section{Overall Findings}

The first aim of the current investigation was to explore the differences between patients prescribed or not prescribed opioids. Patients prescribed and not prescribed an opioid were not significantly different based on age, sex, race, employment status or smoking status, mental health diagnoses, pain diagnoses, family history of substance abuse, number of children or times married, duration of chronic pain, or total scores on measures of pain severity (MPQSF), pain disability (PDI), and fear of movement (TSK). The lack of demographic differences between these two groups is alone an interesting finding. Previous research has demonstrated that nurses and physicians often are influenced by age, sex, and race when making prescribing decisions (Burgess et al., 2008; Hirsh, George, \& Robinson, 2009; Olsen, Daumit, \& Ford, 2006; Pletcher, Kertesz, Kohn, \& Gonzales, 2008; Tamayo-Sarver, Hinze, Cydulka, \& Baker, 2003; Weisse, Sorum, Sanders, \& Syat, 2001). The current study may not have detected differences in these demographic factors due to having a smaller sample size $(N=151)$ than other similar 
investigations (e.g., $N=382$ in Burgess et al., 2008), especially in regard to race. Interestingly, only one of the studies just mentioned utilized patients presenting to a primary care office (i.e., Weisse, Sorum, Sanders, \& Syat, 2001) with a sample size of 111, and this investigation did not find any significant differences in prescribing based on patient sex or ethnicity/race, but did find a significant interaction between physician sex and gender/racial and ethnicity cues. The other investigations just mentioned were conducted utilizing patients presenting to emergency departments for care (i.e., Pletcher, Kertesz, Kohn, \& Gonzales, 2008; Tamayo-Sarver, Hinze, Cydulka, \& Baker, 2003) or did not occur with "real" patients and instead utilized virtual humans or had physicians read paper vignettes about patients (i.e., Burgess et al., 2008; Hirsh, George, \& Robinson, 2009). Lastly, Olsen, Daumit, and Ford (2006) based their findings on the National Ambulatory Medical Care Survey, which includes both ambulatory and outpatient departments. The lack of significance between age, sex, and ethnicity/race found in this investigation and the study conducted by Weisse et al. (2001) suggests that there may be something unique about Family Medicine patient populations; however, additional analyses are necessary to determine if there were any interaction effects within the current investigation.

The groups differed based on their pain rating at the time of the opioid risk evaluation, history of abuse or substance abuse, relationship status, level of education, and scores on the PCS, SOAPP-R, and BDI-II. Patients not prescribed an opioid were more likely to have higher pain ratings at the time of the evaluation, report a history of abuse, be single or divorced, and have higher scores on the PCS, SOAPP-R, and BDI-II. These results are not surprising as all of these variables are considered when deciding risk status, and have associations with opioid or substance abuse in the literature. A patient presenting to clinic with these characteristics (i.e., anxious/depressed, exhibiting misuse or diversion behaviors) likely is more complicated than a 
patient without these particular problems, and may signal a higher risk to the evaluator or physician. It is difficult to determine how the patient interacted with the psychology team or physician, but research findings suggest that patients with a more complicated presentation are more difficult to treat (Matthias et al., 2010), and these characteristics may be the most apparent, as compared to other variables that were examined.

The second aim of this study was to examine the influence of opioid risk status on opioid prescribing. Patient care has improved and healthcare costs have been reduced with the inclusion of interdisciplinary integrated care (Blumenthal et al., 2005; van Orden, Hoffman, Haffmans, Spinhoven, \& Hoencamp, 2009); however, it was unclear if physicians incorporated the recommendations from other professionals into their decision making process and how it may affect their treatment of chronic pain patients. The results of this aim suggest that physicians integrate the recommendations of the psychological team into their decision making process when prescribing opioid analgesics. It is possible that having a variety of factors consolidated into a singular risk status may be beneficial to physicians in understanding their patient's opioid abuse potential as many physicians lack training in discerning opioid abuse and diversion (Matthias et al., 2010; Richeimer, 2005), and having to consider multiple risk factors, instead of a singular risk status may be overwhelming, time consuming, and unhelpful.

The third aim was to determine if any other factors outlined in the literature were predictive of opioid prescribing. After identifying risk status as a significant predictor, it was important to further evaluate other variables influence on opioid prescribing. Several variables significantly predicted opioid prescribing as expected based on the literature, specifically history of substance abuse, level of education, relationship status, and scores on the SOAPP-R, BDI-II, and PCS. These variables have been identified as factors related to potential opioid abuse and 
therefore were expected to be significant predictors (Breitbart et al., 1997; Chou, 2009; Passik, Messina, Golsorkhi, \& Xie, 2010; Pergolizzi et al., 2012; Portenoy, 1996; Rice et al., 2012; Turk, Swanson, \& Gatchel, 2008; Weaver \& Schnoll, 2002; Ziegler, 2005). Interestingly, patients' history of abuse also significantly predicted opioid prescribing, with patients reporting a history of physical or sexual abuse being less likely to be prescribed an opioid. History of preadolescent sexual abuse has been identified as a potential risk factor for substance abuse (Kendler, Bulik, Silberg, Hettema, Myers, \& Prescott, 2000; Mullen, Martin, Anderson, Romans, \& Herbison, 1993), but has not been associated with opioid prescribing or specifically for opioid abuse. For this study, the patients' history of abuse included both sexual and physical abuse identified by the patient, demonstrating the potential influence of this history on opioid prescribing. It is unclear whether these patients should or should not be prescribed an opioid; however, a history of abuse has been associated with mental health and substance abuse problems (Beitchman et al., 1992; Mullen, Martin, Anderson, Romans, \& Herbison, 1996; Nikulina, Widom, \& Brzustowicz, 2012), as well as a number of medical problems, including obesity, chronic headaches, chronic pelvic pain, somatization, and certain surgical procedures (e.g., hysterectomy; Felitti, 1991; Irish, Kobayashi, \& Delahanty, 2010; Longstreth, 1994; Springs \& Friedrich, 1992). When considering the potential psychological comorbidities associated with abuse, it is possible that patients presenting with a history of abuse also had additional problems. This presentation may result in the psychology team increasing the patient's risk status and recommending alternative treatments prior to prescribing opioids.

The final aim was to utilize the significant factors to develop a predictive model. Unexpectedly, while many factors were significant predictors independently, when added to the full model, these factors no longer were significant. Results of multivariate logistic regression 
analysis demonstrated that the predictor variables likely share variance with the risk status assigned to each patient as many of these variables were utilized to determine said status; however, substance abuse history remained significant until included with risk status. Therefore, the best predictor of opioid prescribing appears to be the risk status assigned by the psychological team, as well as substance abuse history, when considered independently; however, when included alone, risk status demonstrated better model fit than when included with substance abuse or substance abuse on its own. These results suggest the effectiveness in providing supplemental information to physicians to aid in opioid prescribing decisions, and may act to reduce prescribing bias based on demographic factors (i.e., age, ethnicity/race, gender). Physicians have reported having less training and confidence in treating chronic pain and identifying opioid abuse and diversion (Glajchen, 2001; Matthias, 2010; Richeimer, 2005). By providing physicians with a condensed version of the various risk factors through the singular risk status, they are able to more easily utilize evidence-based factors in their decision-making process, potentially reduce prescribing bias, and possibly avoiding conflict with their patients.

\section{Exploratory Analyses}

Selection bias was thought to be a potential area of concern due to the policy related to referrals to the psychology team. The WVU Family Medicine protocol requires resident physicians to refer all patients requesting or being considered for long-term opioid therapy; however, attending physicians are strongly encouraged, but not required. While there were more referrals from resident physicians, there was no significant difference in opioid prescribing based on physician training level. Additionally, after examining the crosstabulations between physician training level and risk status, the outcome of the evaluations for the referred patients was equivalent across risk status and physician training level, with no significant differences. 
This finding suggests that when attending physicians refer patients for an evaluation the patients likely are not all psychosocially complex, as previously assumed. The attending physicians refer an array of patients, or at least that is how it appears post opioid risk status. See Table 17 for this information.

A secondary concern involved the different levels of training within the psychology team (i.e., graduate students, predoctoral interns, postdoctoral fellows, and licensed psychologists) assigning the risk status and the potential for bias when assigning. It is possible that there is variability in how the evaluators' assigned risk status as there is an element of clinical judgment inherent in each evaluation; however, there was no significant difference between opioid risk status and evaluator training level. This finding suggests that within the study sample, evaluators from the four training levels assigned risk statuses in relatively equivalent numbers.

\section{Limitations and Strengths}

Due to the retrospective design of the current investigation, there was little control over what was asked of the patients and what was included in the opioid risk evaluation. While there was relative consistency across the format of the evaluations, some information had to be extrapolated from the patient's medical record. Unfortunately, some patients neglected to fully complete questionnaires resulting in missing data, which could not be recovered. In addition, the information about opioid prescribing was based on the decision made at the next appointment following the opioid risk evaluation, and does not account for any changes, which may have occurred, following that appointment or other classes of medications prescribed. Lastly, due to insufficient data, the information about patients' Board of Pharmacy review and urine drug screens were unable to be analyzed. It seemed that the majority of patients in this sample did not have the Board of Pharmacy review noted in their medical record, though it seemed to increase 
in the evaluations conducted following July 2012, which coincides with new guidelines for reporting (West Virginia Code, 2012). In regard to the urine drug screen, many patients did not have an initial screen in their records, and few patients had any follow-up screens. Inclusion of this information may have modified the results; however, due to the lack of information in the medical record, it may be that physicians were not utilizing this information when prescribing.

Unfortunately, there was little information about the opioid prescribing practices of physicians in the clinic prior to the institution of the opioid risk evaluations in late 2010. It could be assumed that the opioid prescribing practices were likely less stringent as it was a different socio-political climate and opioid abuse was not as evident at that time. Only in the past four years has the focus shifted to prescribing less and more carefully and creating more stringent guidelines for chronic opioid therapy through the recommendation of major pain associations (i.e., Neuropathic Pain Special Interest Group of the International Association for the Study of Pain; European Federation of Neurological Societies Task Force; Attal et al., 2010; Dworkin et al., 2010). Therefore, physicians may have been more lenient with prescribing; however, there is not definitive information available to determine if this assumption is accurate or to determine what was predictive of opioid prescribing at that time.

The WVU Department of Family Medicine psychology team has a specific format for opioid risk evaluations based upon the current research available regarding opioid abuse and misuse; however, the final decision of assigning a risk status is decided utilizing a variety of information, as well as clinician judgment. It is unclear how each clinician may be utilizing the information or which information is weighted more heavily when assigning risk status. As a result, there is an inherent amount of variation within the opioid risk evaluations. 
Information from the physicians' perspective regarding what he or she consciously considers when prescribing opioids would have been a helpful addition to the current data. By understanding what the physician considers and comparing it to the current information, potential discrepancies could have been identified. Additionally, it would be interesting to examine how heavily the physicians weighed various aspects of a patient's presentation when prescribing, especially the opioid risk status. Unfortunately, due to the nature of the current investigation, obtaining information from physicians would have been difficult and tainted by the retrospective design. Some resident physicians have graduated from the program making them unavailable for questioning and unless the physicians were asked to evaluate cases on a patientby-patient basis it may lead to overgeneralizations or inaccurate self-critiques on their prescribing behaviors.

Using patients at a family medicine clinic was a particular strength of this study; however, due to the ethnic/racial makeup of West Virginia, lack of diversity was a limitation. The current study would benefit from the inclusion of different races and ethnicities as the sample was $96.7 \%$ white and $3.3 \%$ black. This limitation is consistent with the ethnic/racial profile of West Virginia (i.e., 94\% Caucasian, 6\% Other; U.S. Census Bureau, 2012), and should be addressed in future research.

\section{Future Research}

The current project is the first known study of the influence of interdisciplinary recommendations on opioid prescribing. With the growing emphasis on patient-centered care and interdisciplinary treatment, future work in this same area likely would improve professional interactions and team based approaches to treating complicated chronic pain patients. One future direction of research might include designing a prospective longitudinal study that includes 
qualitative information, specifically the physicians' perspective when prescribing to determine which factors are considered and to what degree when making difficult prescribing decisions. Additionally, certain variables, which likely are influential in prescribing (i.e., Board of Pharmacy review, urine drug screen), often were not mentioned or not completed for patients making it difficult to determine if physicians utilized this information when prescribing. In 2012, West Virginia introduced a new law requiring the inclusion of this information in medical records for patients prescribed long term opioid medication (West Virginia Code, 2012). This information should be included in future research to determine each variables predictive value in opioid prescribing, especially as it relates to risk status.

Other future work in this area may further examine the opioid risk evaluations to create a more consolidated approach and remove some of the inherent variation due to clinician judgment. By deconstructing the evaluation, clinicians may be able to create a screener to determine which patients can be assessed through a brief evaluation instead of the lengthy full version. This assessment of the evaluation material also may help to focus the opioid risk evaluations on the factors that seem to be most indicative of opioid misuse and abuse. Additionally, inclusion of feedback from physicians that specifies which information they are likely to attend to when prescribing may allow clinicians to create a shorter, more concise report for physician use. Lastly, it is necessary to determine the accuracy of the opioid risk status through future follow-up with patients. This information could be determined through Board of Pharmacy reviews, urine drug screens, and brief follow-up screenings with patients. This information may prove difficult to obtain as some patients may choose to receive care elsewhere; however, it could be beneficial in understanding the static and dynamic risk factors over time. 
After better understanding physician perspectives and the evaluation itself, a cost analyses would be a viable next step to better understand the impact on the larger healthcare system. Previous research has shown that integrated care reduces treatment time, and results in fewer appointments and lower costs than traditional patient referral to offsite mental health centers (van Orden et al., 2009); however, it is unclear what impact these evaluations may have on costs associated with the treatment of chronic pain. By better understanding the potential influence on costs, the feasibility of utilizing risk evaluations could be assessed.

\section{Conclusions}

The aims of this study were to: (a) explore the differences between patients prescribed or not prescribed opioids, (b) examine the influence of opioid risk status on opioid prescribing, (c) determine if any other factors outlined in the literature were predictive of opioid prescribing, and (d) utilize these factors to develop a predictive model. To achieve these goals, electronic medical record reviews were conducted on 151 chronic pain patients seeking long term opioid therapy. Using a series of univariate logistic regressions, several factors were identified as being significantly predictive of opioid prescribing; however, only two variables remained significant when included in the full model, substance abuse and risk status.

With the current socio-political agenda in regard to healthcare, (i.e., focus on reducing opioid abuse and overdose deaths, as well as emphasizing interdisciplinary care), the current investigation provides important information about physicians' opioid prescribing and utilization of other professionals' recommendations. Based on the results, opioid prescribing was significantly influenced by the opioid risk evaluation conducted by the psychology team at the WVU Department of Family Medicine. This information is promising for interdisciplinary treatment teams as it seems physicians integrate the professional assessment of other experts into 
their decision making process. Additionally, it suggests that physicians can modify their bias of prescribing based on age, ethnicity/race, and sex, as found in other studies, to instead rely on research-based opioid risk evaluations. The opportunity for additional information in an area in which physicians often lack training and describe having difficulty providing treatment (Bendtsen, Hensing, Ebeling, \& Schedin, 1999; Bertakis, Azari, \& Callahan, 2003; Matthias et al., 2010) may allow for physicians to utilize information from other professionals to learn about alternative treatment options in the process.

What remains unanswered by the current study is if this modification to utilize opioid risk status for prescribing is an improvement for patient care, a means to protect the physician from litigation, or a potential bias against patients that may have psychosocial problems? Patients that are high risk for opioid abuse still can be prescribed opioid medication (Weaver \& Schnoll, 2002), but the inherent risks for the patient and physician increase resulting in increased scrutiny of the patient and intensified monitoring responsibilities for the physician. The increased demand on physician time may lead physicians to simply deny prescriptions for those patients that may benefit, even if high risk. Alternatively, the utilization of risk status and expert pain recommendations may encourage physicians to try alternative treatment options (e.g., antidepressant or anticonvulsant medication, physical therapy, psychotherapy) prior to prescribing opioid medication, which arguably is a better first line of treatment than chronic opioid therapy and may lead to improved patient functioning that is unlikely to be achieved with chronic opioid therapy alone.

The current study illustrates the effectiveness of providing physicians with supplemental information, specifically in an area in which they tend to have less training and confidence (i.e., chronic pain treatment, identifying opioid abuse and diversion). By utilizing risk status to aid 
physician's prescribing decisions, the inclusion of evidence-based factors into their decisionmaking process is simplified. Physicians can rely on the expert evaluation of a colleague, while potentially eliminating some of their own inherent bias and possibly improving patient care. On a larger systems level, understanding how opioid risk status and other factors affect physicians' opioid prescribing, may reveal how to modify physician bias not only in the realm of opioid prescribing, but other aspects of patient care. If the inclusion of interdisciplinary care and collaborative treatment reduces physician bias and eases the decision-making process, it lends the physician more time to spend on other aspects of patient care or other cases. With the influx of patients into primary care expected with the introduction of the Affordable Care Act, increasing physician efficiency and providing support is an essential part of helping to make this policy successful. Thus, opioid risk evaluations demonstrate one aspect of support that psychology can provide to physicians and the healthcare system as a whole. 


\section{References}

Agresti, A. (2007). Logistic regression. In An introduction to categorical data analysis (2nd ed.), (pp. 99-172). Hoboken, NJ: John Wiley \& Sons, Inc.

Arnow, B. A., Blasey, C. M., Lee, J., Fireman, B., Hunkeler, E. M., Dea, R., . . Hayward, C. (2009). Relationships among depression, chronic pain, chronic disabling pain, and medical costs. Psychiatric Services, 60, 344-350.

Attal, N., Cruccu, G., Baron, R., Haanpää, M., Jensen, T. S., \& Nurmikko, T. (2010). EFNS guidelines on the pharmacological treatment of neuropathic pain: 2010 revision. European Journal of Neurology, 17, 1113-1123.

Bair, M. J., Wu, J., Damush, T. M., Sutherland, J. M., \& Kroenke, K. (2008). Association of depression and anxiety alone and in combination with chronic musculoskeletal pain in primary care patients. Psychosomatic Medicine, 70, 890-897.

Barkin, R. L., Schwer, W. A., \& Barkin, S. J. (2007). Pharmacotherapeutic management of acute and chronic pain. In R. E. Rakel (Ed.), Textbook of family medicine (7th ed.), (pp. 305316). Philadelphia, PA: Saunders Elsevier.

Bassols, A., Bosch, F., Campillo, M., Canellas, M., \& Banos, J. E. (1999). An epidemiological comparison of pain complaints in the general population of Catalonia (Spain). Pain, 83, 9-16.

Beck, A. T., Steer, R. A., \& Brown, O. K. (1996). Beck Depression Inventory manual (2nd ed.). San Antonio, TX: Psychological Corporation.

Beitchman, J. H., Zucker, K. J., Hood, J. E., daCosta, G. A., Akman, D., \& Cassavia, E. (1992). A review of the long-term effects of child sexual abuse. Child Abuse \& Neglect, 16, 101118. 
Bendel, R. B., \& Afifi, A. A. (1977). Comparison of stopping rules in forward regression. Journal of the American Statistical Association, 72, 46-53.

Bendtsen, P., Hensing, G., Ebeling, C., \& Schedin, A. (1999). What are the qualities of dilemmas experienced when prescribing opioids in general practice? Pain, 82, 89-96.

Bennett, D. A. (2001). How can I deal with missing data in my study? Australian and New Zealand Journal of Public Health, 25, 464-469.

Bennett, D. S., \& Carr, D. B. (2002). Opiophobia as a barrier to the treatment of pain. Journal of Pain and Palliative Care Pharmacotherapy, 16, 105-109.

Bertakis, K. D., Azari, R., \& Callahan, E. J. (2003). Patient pain: Its influence on primary care physician-patient interaction. Family Medicine Journal, 35, 119-123.

Birnbaum, H. G., White, A. G., Schiller, M., Waldman, T., Cleveland, J. M., \& Roland, C. L. (2011). Societal costs of prescription opioid abuse, dependence, and misuse in the United States. Pain Medicine, 12, 657-667.

Blumenthal, J. A., Sherwood, A., Babyak, M. A., Watkins, L. L., Waugh, R., Georgiades, A.,...Hinderliter, A. (2005). Effects of exercise and stress management training on markers of cardiovascular risk in patients with ischemic heart disease: A randomized control trial. JAMA, 293, 1626-1634.

Bowsher, D., Rigge, M., \& Sopp, L. (1991). Prevalence of chronic pain in the British population: A telephone survey of 1037 households. The Pain Clinic, 4, 223-230.

Brattberg, G., Thorslund, M., \& Wikman, A. (1989). The prevalence of pain in the general population: The results of a postal survey in a county in Sweden. Pain, 37, 215-222. 
Breitbart, W., Rosenfeld, B., Passik, S., Kaim, M., Funesti-Esch, J., \& Stein, K. (1997). A comparison of pain report and adequacy of analgesic therapy in ambulatory AIDS patients with and without a history of substance abuse. Pain, 72, 235-243.

Buckley, D. I., Calvert, J. F., Lapidus, J. A., \& Morris, C. D. (2010). Chronic opioid therapy and preventive services in rural primary care: An Oregon rural practice-based research network study. Annals of Family Medicine, 8, 237-244.

Burckhardt, C. S., \& Bjelle, A. (1994). A Swedish version of the Short-Form McGill Pain Questionnaire. Scandinavian Journal of Rheumatology, 23, 77-81.

Burgess, D. J., Crowley-Matoka, M., Phelan, S., Dovidio, J. F., Kerns, R., Roth, C.,...van Ryn, M. (2008). Patient race and physicians' decisions to prescribe opioids for chronic low back pain. Social Science \& Medicine, 67, 1852-1860.

Butler, S. F., Fernandez, K., Benoit, C., Budman, S. H., \& Jamison, R. N. (2008). Validation of the revised Screener and Opioid Assessment for Patients with Pain (SOAPP-R). Journal of Pain, 9, 360-372.

Carr, D., \& Goudas, L. (1999). Acute pain. Lancet, 353, 2051-2058.

Carver, C. S. (1997). You want to measure coping but your protocol's too long: Consider the Brief COPE. International Journal of Behavioral Medicine, 4, 92-100.

Center for Disease Control and Prevention. (2011a). Policy impact: Prescription painkiller overdoses. Atlanta, GA: U.S. Department of Health and Human Services. Retrieved from http://www.cdc.gov/homeandrecreationalsafety/rxbrief/index.html.

Center for Disease Control and Prevention. (2011b). Vital signs: Overdoses of prescription opioid pain relievers-United States, 1999-2008. Morbidity and Mortality Weekly Report, 60, 1-6. 
Center for Disease Control and Prevention. (2011c). Vital signs: Prescription painkiller overdoses in the U.S. Atlanta, GA: National Center for Injury Prevention and Control. Retrieved from http://www.cdc.gov/vitalsigns/pdf/2011-11-vitalsigns.pdf.

Cherry, D. K., Burt, C. W., \& Woodwell, D. A. (2003). National ambulatory medical care survey: 2001 summary. Advance Data, 11, 1-44.

Chou, R. (2009). 2009 clinical guidelines from the American Pain Society and the American Academy of Pain Medicine on the use of chronic opioid therapy in chronic noncancer pain. Polish Archives of Internal Medicine, 119, 7-8.

Chou, R., Atlas, S. J., Stanos, S. P., \& Rosenquist, R. W. (2009). Nonsurgical interventional therapies for low back pain. Spine, 34, 1078-1093.

Clark, M. E., Kori, S. H., \& Brockel, J. (1996). Kinesiophobia and chronic pain: Psychometric characteristics and factor analysis of the Tampa Scale. Presented at the annual scientific meeting of the American Pain Society, Abstracts 15, 77, Washington, DC.

Clarke, K. A., \& Iphofen, R. (2005). Believing the patient with chronic pain: A review of the literature. British Journal of Nursing, 14, 490-493.

Cleeland, C. S., Cleeland, L. M., Dar, R., \& Rinehardt, L. C. (1986). Factors influencing physician management of cancer pain. Cancer, 58, 796-800.

Clinical Standards Advisory Group Committee. (1994). Back pain: Report of a CSAG committee on back pain. London, UK: HMSO.

Coase, R. H. (1937). The nature of the firm. Economica, 4, 386-405.

Croft, P., Rigby, A. S., Boswell, R., Schollum, J., \& Silman, A. (1993). The prevalence of chronic widespread pain in the general population. Journal of Rheumatology, 20, 710713. 
Crofford, L. J., Rowbotham, M. C., Mease, P. J., Russell, I. J., Dworkin, R. H., Corbin, A. E.,...Sharma, U. (2005). Pregabalin for the treatment of fibromyalgia syndrome: Results of a randomized, double-blind, placebo-controlled trial. Arthritis and Rheumatism, 52, 1264-1273.

Crombie, I. K., \& Davies, H. T. O. (1998). Selection bias in pain research. Pain, 74, 1-3.

Crook, J., \& Browne, G. (1984). The prevalence of pain complaints in a general population. Pain, 18, 299-314.

DeBerard, M. S., Masters, K. S., Colledge, A. L., Schleusener, R. L., \& Schlegel, J. D. (2001). Outcomes of posterolateral lumbar fusion in Utah patients receiving workers' compensation: A retrospective cohort study. Spine, 26, 738-746.

Deyo, R. A., Gray, D. T., Kreuter, W., Mirza, S., \& Martin, B. I. (2005). United States trends in lumbar fusion surgery for degenerative conditions. Spine, 30, 1441-1445.

Dixon, K. E., Keefe, F. J., Scipio, C. D., Perri, L. M., \& Abernethy, A. P. (2007). Psychological interventions for arthritis pain management in adults: A meta-analysis. Journal of Health Psychology, 26, 241-50.

Dobscha, S. K., Corson, K., Flores, J. A., Tansill, E. C., \& Gerrity, M. S. (2008). Veterans affairs primary care clinicians' attitudes toward chronic pain and correlates of opioid prescribing rates. Pain Medicine, 9, 564-571.

Drug Enforcement Administration Office of Diversion Control. (2011). Questions and answers: State prescription monitoring programs. Springfield, VA: U.S. Department of Justice. Retrieved from http://www.deadiversion.usdoj.gov/faq/rx_monitor.htm.

Dworkin, R. H., O’Connor, A. B., Audette, J., Baron, R., Gourlay, G. K., Haanpää, M. L.,...Wells, C. D. (2010). Recommendations for the pharmacological management of 
neuropathic pain: An overview and literature update. Mayo Clinic Proceedings, 85 (Suppl), S3-S14.

Edlund, M. J., Sullivan, M., Steffick, D., Harris, K. M., \& Wells, K. B. (2007). Do users of regularly prescribed opioids have higher rates of substance use problems than nonusers? Pain Medicine, 8, 647-656.

Felitti, V.J. (1991). Long-term medical consequences of incest, rape, and molestation. Southern Medical Journal, 84, 328-331.

Field, A. (2009). Logistic regression. In Discovering statistics using SPSS (3 ${ }^{\text {rd }}$ ed.), (pp. 264315). London, UK: Sage Publications, Ltd.

Flor, H., Fydrich, T., \& Turk, D. C. (1992). Efficacy of multidisciplinary pain treatment centers: A meta-analytic review. Pain, 49, 221-230.

Food and Drug Administration Department of Health and Human Services. (2008). FDA identifies first steps in requirements for safety plans for certain drugs and biologics. Silver Spring, MD: U.S. Department of Health and Human Services. Retrieved from http://www.fda.gov/NewsEvents/Newsroom/PressAnnouncements/2008/ucm116872.htm.

French, D. J., France, C. R., Vigneau, F., French, J. A., \& Evans, R. T. (2007). Fear of movement/(re)injury in chronic pain: A psychometric assessment of the original English version of the Tampa Scale for Kinesiophobia (TSK). Pain, 127, 42-51.

Fritzell, P., Hagg, O., Wessberg, P., \& Nordwall, A. (2001). Lumbar fusion versus nonsurgical treatment for chronic low back pain: A multicenter randomized controlled trial from the Swedish Lumbar Spine Study Group. Spine, 26, 2521-2532. 
Furlan, A. D., Sandoval, J. A., Mailis-Gagnon, A., \& Tunks, E. (2006). Opioids for chronic noncancer pain: A meta-analysis of effectiveness and side effects. Canadian Medical Association Journal, 174, 1589-1594.

Furlan, A. D., van Tulder, M., Cherkin, D., Tsukayama, H., Lao, L., Koes, B., \& Berman, B. (2005). Acupuncture and dry-needling for low back pain: An updated systematic review within the framework of the Cochrane collaboration. Spine, 30, 944-963.

Garson, D. (2010). Logistic Regression: Footnotes, from North Carolina State University. Available at: http:/faculty.chass.ncsu.edu/garson/PA765/logistic.htm. Accessed on September, 2013.

Gaskin, D. J., \& Richard, P. (2012). The economic costs of pain in the United States. Journal of Pain, 13, 715-724.

Gilron, I., \& Max, M. B. (2005). Combination pharmacotherapy for neuropathic pain: Current evidence and future directions. Expert Review of Neurotherapeutics, 5, 823-830.

Gilson, A. M., Ryan, K. M., Joranson, D. E., \& Dahl, J. L. (2004). A reassessment of trends in the medical use and abuse of opioid analgesics and implications for diversion control: 1997-2002. Journal of Pain and Symptom Management, 28, 176-188.

Glajchen, M. (2001). Chronic pain: Treatment barriers and strategies for clinical practice. Journal of American Board of Family Practice, 14, 211-218.

Grönblad, M., Hupli, M., Wennerstrand, P., Jarvinen, E., Lukinmaa, A., Kouri, J. P., \& Karaharju, E. O. (1993). Intercorrelation and test-retest reliability of the Pain Disability Index (PDI) and the Oswestry Disability Questionnaire (ODQ) and their correlation with pain intensity in low back pain patients. Clinical Journal of Pain, 9, 189-195. 
Guay, D. R. P. (2001). Adjunctive agents in the management of chronic pain. Pharmacotherapy, 21, 1070-1081.

Guzman, J., Esmail, R., Karjalainen, K., Malmivaara, A., Irvin, E., \& Bombardier, C. (2001). Multidisciplinary rehabilitation for chronic low back pain: Systematic review. British Medical Journal, 322, 1511-1516.

Haake, M., Müller, H. H., Schade-Brittinger, C., Basler, H. D., Schafer, H., Maier, C.,...Molsberger, A. (2007). German Acupuncture Trials (GERAC) for chronic low back pain: Randomized, multicenter, blinded, parallel-group trial with three groups. Archives of Internal Medicine, 167, 1892-1898.

Haley, W., Turner, J., \& Romano, J. (1985). Depression in chronic pain patients: Relation to pain, activity, and sex differences. Pain, 23, 337-343.

Hanley, J. A., \& McNeil, B. J. (1982). The meaning and use of the area under an ROC curve. Radiology, 143, 27-36.

Hansen, R. N., Oster, G., Edelsberg, J., Woody, G. E., \& Sullivan, S. D. (2011). Economic costs of nonmedical use of prescription opioids. Clinical Journal of Pain, 27, 194-202.

Hardt, J., Jacobsen, C., Goldberg, J., Nickel, R., \& Buchwald, D. (2008). Prevalence of chronic pain in a representative sample in the United States. Pain Medicine, 9, 803-812.

Harris, C. A., \& D’Eon, J. L. (2008). Psychometric properties of the Beck Depression InventorySecond Edition (BDI-II) in individuals with chronic pain. Pain, 137, 609-622.

Henschke, N., Ostelo, R. W., van Tulder, M. W., Vlaeyen, J. W., Morley, S., Assendelft, W. J., \& Main, C. J. (2010). Behavioural treatment for chronic low-back pain. Cochrane Database Systematic Review, 20, CD002014. 
Hirsh, A. T., George, S. Z., \& Robinson, M. E. (2009). Pain assessment and treatment disparities: A virtual human technology investigation. Pain, 143, 106-113.

Hoffman, B. M., Papas, R. K., Chatkoff, D. K., \& Kerns, R. D. (2007). Meta-analysis of psychological interventions for chronic low back pain. Journal of Health Psychology, 26, $1-9$.

Hosmer, D. W., \& Lemeshow, S. (2000). Multiple logistic regression. In Applied logistic regression (2 ${ }^{\text {nd }}$ ed.), (pp. 31-46), New York, NY: John Wiley \& Sons, Inc.

Howell, D. C. (2010). Logistic regression. In Statistical methods for psychology $\left(7^{\text {th }}\right.$ ed.), (pp. 561-577). Belmont, CA: Wadsworth, Cengage Learning.

Hutchinson, K., Moreland, A. M., de Williams A. C. C., Weinman, J., \& Horne, R. (2007). Exploring beliefs and practice of opioid prescribing for persistent non-cancer pain by general practitioners. European Journal of Pain, 11, 93-98.

IMS Health. (2012). Overall utilization of pharmaceuticals by state. Retrieved from http://www.imshealth.com/portal/site/ims.

International Association for the Study of Pain. (1986). Classification of chronic pain. Pain, 3 (Suppl), S1-S226.

Irish, L., Kobayashi, I., \& Delahanty, D. L. (2010). Long-term physical health consequences of childhood sexual abuse: A meta-analytic review. Journal of Pediatric Psychology, 35, $450-461$.

James, F. R., Large, R. G., Bushnell, J. A., \& Wells, J. E. (1991). Epidemiology of pain in New Zealand. Pain, 44, 279-283.

Jamison, R. N., Kauffman, J., \& Katz, N. P. (2000). Characteristics of methadone maintenance patients with chronic pain. Journal of Pain and Symptom Management, 19, 53-62. 
Jensen, M., \& Patterson, D. R. (2006). Hypnotic treatment of chronic pain. Journal of Behavioral Medicine, 29, 95-124.

Johnson, M., \& Martinson, M. (2007). Efficacy of electrical nerve stimulation for chronic musculoskeletal pain: A meta-analysis of randomized controlled trials. Pain, 130, 157165.

Kabat-Zinn, J. (1990). The Applications: Taking on the Full Catastrophe. In Full catastrophe living: Using the wisdom of your body and mind to face stress, pain and illness, (pp. 277332). New York, NY: Delacorte Press.

Katz, P. (2008). Chronic pain management: An appropriate use of opioid analgesics. American College of Physicians, Internist Extra, 1-8.

Kendler, K. S., Bulik, C. M., Silberg, J., Hettema, J. M., Myers, J., \& Prescott, C. A. (2000). Childhood sexual abuse and adult psychiatric and substance use disorders in women: An epidemiological and co-twin control analysis. Archives of General Psychiatry, 57, 953959.

Khadilkar, A., Odebiyi, D. O., Brosseau, L., \& Wells, G. A. (2008). Transcutaneous electrical nerve stimulation (TENS) versus placebo for chronic low-back pain. Cochrane Database Systematic Review, 4, CD003008.

Little, R. J. A., \& Rubin, D. B. (2002). Bayes and multiple imputation. In Statistical analysis with missing data (2nd ed.), (pp. 200-223). New York, NY: John Wiley \& Sons.

Longstreth, G. F. (1994). Irritable bowel syndrome and chronic pelvic pain. Obstetrical \& Gynecological Survey, 49, 505-507. 
Luijsterburg, P. A., Verhagen, A. P., Ostelo, R. W, van Os, T. A., Peul, W. C., \& Koes, B.W. Effectiveness of conservative treatments for the lumbosacral radicular syndrome: A systematic review. European Spine Journal, 16, 881-899.

Menard, S. (2010). Logistic regression diagnostics and problems of inference. In Logistic Regression: From Introductory to Advanced Concepts and Applications, (pp. 125-144). Thousand Oaks, CA: Sage Publications, Inc.

Manchikanti, L. (2004). The growth of interventional pain management in the new millennium: A critical analysis of utilization in the medicare population. Pain Physician, 7, 465-482.

Manheimer, E., White, A., Berman, B., Forys, K., \& Ernst, E. (2005). Meta-analysis: Acupuncture for low back pain. Annals of Internal Medicine, 142, 651-663.

Matthias, M. S., Parpart, A. L., Nyland, K. A., Huffman, M. A., Stubbs, D. L., Sargent, C., \& Bair, M. J. (2010). The patient-provider relationship in chronic pain care: Providers' perspectives. Pain Medicine, 11, 1688-1697.

Mason, L., Moore, R. A., Edwards, J. E., McQuay, H. J., Derry, S., \& Wiffen, P. J. (2004). Systematic review of efficacy of topical rubefacients containing salicylates for the treatment of acute and chronic pain. British Medical Journal, 328, 995.

McCracken, L. M., Gross, R. T., Aikens, J., \& Carnrike, C., Jr. (1996). The assessment of anxiety and fear in persons with chronic pain: A comparison of instruments. Behaviour Research and Therapy, 34, 927-933.

Melzack, R. (1987). The short-form McGill pain questionnaire. Pain, 30, 191-197.

Mickey, J., \& Greenland, S. (1989). A study of the impact of confounder-selection criteria on effect estimation. American Journal of Epidemiology, 129, 125-137.

Miller, R. P., Kori, S. H., \& Todd, D. D. (1991). The Tampa Scale. Unpublished Report, Tampa. 
Montgomery, G. H., DuHamel, K. N., \& Redd, W. H. (2000). A meta-analysis of hypnotically induced analgesia: How effective is hypnosis? International Journal of Clinical and Experimental Hypnosis, 48, 138-153.

Morgan, J. P. (1985). American opiophobia: Customary underutilization of opioid analgesics. Advances in Alcohol \& Substance Abuse, 5, 163-173.

Morley, S., Eccleston, C., \& Williams, A. (1999). Systematic review and meta-analysis of randomized controlled trials of cognitive behavior therapy and behaviour therapy for chronic pain in adults, excluding headache. Pain, 80, 1-13.

Mullen, P. E., Martin, J. L., Anderson, J. C., Romans, S. E., \& Herbison, G. P. (1993). Childhood sexual abuse and mental health in adult life. British Journal of Psychiatry, $163,721-732$.

Mullen, P. E., Martin, J. L., Anderson, J. C., Romans, S. E., \& Herbison, G. P. (1996). The longterm impact of the physical, emotional, and sexual abuse of children: A community study. Child Abuse \& Neglect, 20, 7-21.

Nachemson, A. L. (1992). Newest knowledge of low back pain: A critical look. Clinical Orthopaedics and Related Reseach, 279, 8-20.

Nair, H. S., Manchanda, P., \& Bhatia, T. (2010). Aymmetric social interactions in physician prescribing behavior: The role of opinion leaders. Journal of Marketing Research, 47, 883-895.

Nance, P., \& Meythaler, J. (1999). Intrathecal drug therapy. Physical Medicine \& Rehabilitation Clinics of North America, 10, 385-401.

Nathan, J. I. (2008). Chronic pain treatment: A high moral imperative with offsetting personal risks for the physician--A medical student's perspective. Pain Practice, 9, 155-163. 
National Institute on Drug Abuse. (2011). Prescription drugs: Abuse and addiction. NIH Publication Number 11-4881. Retrieved from http://www.drugabuse.gov/sites/default/files/rrprescription.pdf.

Nikulina, V., Widom, C. S., \& Brzustowicz, L. M. (2012). Child abuse and neglect, MAOA, and mental health outcomes: A prospective examination. Biological Psychiatry, 71, 280-281.

Nnoaham, K. E., \& Kumbang, J. (2008). Transcutaneous electrical nerve stimulation (TENS) for chronic pain. Cochrane Database of Systematic Reviews, 3, CD003222.

Nuesch, E., Rutjes, A. W., Husni, E., Welch, V., \& Juni, P. (2009). Oral or transdermal opioids for osteoarthritis of the knee or hip. Cochrane Database of Systematic Reviews, 4, CD003115.

Nwokeji, E. D., Rascati, K. L., Brown, C. M., \& Eisenberg, A. (2007). Influences of attitudes on family physicians' willingness to prescribe long-acting opioid analgesics for patients with chronic nonmalignant pain. Clinical Therapeutics, 29, 2589-2602.

Oesch, P., Kool, J., Hagen, K. B., \& Bachmann, S. (2010). Effectiveness of exercise on work disability in patients with non-acute non-specific low back pain: Systematic review and meta-analysis of randomised controlled trials. Journal of Rehabilitation Medicine, 42, 193-205.

Olsen, Y., Daumit, G. L., \& Ford, D. E. (2006). Opioid prescriptions by U.S. primary care physicians from 1992 to 2001. Journal of Pain, 7, 225-235.

Osborne, J. W. (2013). Dealing with missing or incomplete data: Debunking the myth of emptiness. In Best practices in data cleaning: A complete guide to everything you need to do before and after collecting your data, (pp. 105-138). Louisville, KY: Sage Publications, Inc. 
Osman, A., Barrios, F. X., Gutierrez, P. M., Kopper, B. A., Merrifield, T., \& Grittmann, L. (2000). The Pain Catastrophizing Scale: Further psychometric evaluation with adult samples. Journal of Behavioral Medicine, 23, 351-365.

Osman, A., Barrios, F. X., Kopper, B. A., Hauptmann, W., Jones, J., \& O’Neill, E. (1997). Factor structure, reliability, and validity of the Pain Catastrophizing Scale. Journal of Behavioral Medicine, 10, 263-276.

Pallant, J. (2010). Logistic regression. In SPSS survival manual (3 ${ }^{\text {rd }}$ ed.), (pp. 166-178). New York, NY: Open University Press.

Passik, S. D., Messina, J., Golsorkhi, A., \& Xie, F. (2010). Aberrant drug-related behavior observed during clinical studies involving patients taking chronic opioid therapy for persistent pain and fentanyl buccal tablet for breakthrough pain. Journal of Pain and Symptom Management, 41, 116-125.

Pergolizzi, J. V., Gharibo, C., Passik, S., Labhsetwar, S., Taylor, R., Pergolizzi, J. S., \& MüllerSchwefe, G. (2012). Dynamic risk factors in the misuse of opioid analgesics. Journal of Psychosomatic Research, 72, 443-451.

Pletcher, M. J., Kertesz, S. G., Kohn, M. A., \& Gonzales, R. (2008). Trends in opioid prescribing by race/ethnicity for patients seeking care in U.S. emergency departments. Journal of the American Medical Association, 299, 70-78.

Pollard, C. A. (1984). Preliminary validity study of the Pain Disability Index. Perceptual and Motor Skills, 59, 974.

Portenoy, R. K. (1996). Opioid therapy for chronic nonmalignant pain: A review of the critical issues. Journal of Pain Symptom Management, 11, 203-217. 
Purves, A. M., Penny, K. I., Munro, C., Smith, B. H., Grimshaw, J., Wilson, B.,...Chambers, W. A. (1998). Defining chronic pain for epidemiological research--Assessing a subjective definition. The Pain Clinic, 10, 139-147.

Rice, T. H. (1998). The economics of health reconsidered. Health Economics, 8, 181-182.

Rice, J. B., White, A. G., Birnbaum, H. G., Schiller, M., Brown, D. A., \& Roland, C. L. (2012). A model to identify patients at risk for prescription opioid abuse, dependence, and misuse. Pain Medicine, 13, 1162-1173.

Richeimer, S. H. (2005). Opioids for pain: Risk management. Seminars in Anesthesia, 24, 165169.

Roelofs, J., Goubert, L., Peters, M. L., Vlaeyen, J. W., \& Crombez, G. (2004). The Tampa Scale for Kinesiophobia: Further examination of psychometric properties in patients with chronic low back pain and fibromyalgia. European Journal of Pain, 8, 495-502.

Rosenquist, E. W. K. (2013). Overview of the treatment of chronic pain. Retrieved from http://www.uptodate.com/contents/overview-of-the-treatment-of-chronic-pain.

Schonstein, E., Kenny, D. T., Keating, J., \& Koes, B. W. (2003). Work conditioning, work hardening and functional restoration for workers with back and neck pain. Cochrane Database Systematic Review, 1, CD001822.

See, S., \& Ginzburg, R. (2008). Choosing a skeletal muscle relaxant. American Family Physician, 78, 365-370.

Schafer, J. (1999). Multiple imputation: A primer. Statistical Methods in Medical Research, 8, 315.

Schafer, J., \& Graham, J. (2002). Missing data: Our view of the state of the art. Psychological Methods, 7, 147-177. 
Smith, B. H., Hopton, J. L., \& Chambers, W. A. (1999). Chronic pain in primary care. Family Practice, 16, 475-482.

Smith, B. H., Read, J. R. M., Grimshaw, J. M., Watt, B. G., \& Chambers, W. A. (1996). Researching chronic pain: Identification of a community based sample. The Pain Clinic, 9, 73-76.

Spitzer, W. O., LeBlanc, F. E., \& DePuis, M. (1987). Scientific approach to the assessment and management of activity-related spinal disorders. Spine, 12 (Suppl), S1-S55.

Springs, F. E., \& Friedrich, W. N. (1992). Health risk behaviors and medical sequelae of childhood sexual abuse. Mayo Clinic Proceedings, 67, 527-532.

Sprinkle, S. D., Lurie, D., Insko, S. L., Atkinson, G., Jones, G. L., Logan, A. R., \& Bissada, N. N. (2002). Criterion validity, severity cut scores, and test-retest reliability of the Beck Depression Inventory-II in a university counseling center sample. Journal of Counseling Psychology, 49, 381-385.

Steer, R. A., Clark, D. A., Beck, A. T., \& Ranieri, W. F. (1999). Common and specific dimensions of self-reported anxiety and depression: The BDI-II versus the BDI-IA. Behaviour Research and Therapy, 2, 183-190.

Stiles, R. A., Mick, S. S., \& Wise, C. G. (2001). The logic of transaction costs economics in health care organization theory. Health Care Management Review, 26, 85-92.

Strand, L. I., Ljunggren, A. E., Bogen, B., Ask, T., \& Johnsen, T. B. (2008). The short-form McGill Pain Questionnaire as an outcome measure: Test-retest reliability and responsiveness to change. European Journal of Pain, 12, 917-925. 
Substance Abuse and Mental Health Services Administration. (2007). Treatment episodes data set (TEDS) highlights. Rockville, MD: Office of Applied Studies, National Admissions to Substance Abuse Treatment Services.

Substance Abuse and Mental Health Services Administration. (2008). Results from the 2007 national survey on drug use and health: National findings (NSDUH Series H-34, DHHS Publication No. SMA08-4343). Rockville, MD: Substance Abuse and Mental Health Services Administration, Office of Applied Studies.

Substance Abuse and Mental Health Services Administration. (2009). Results from the 2008 national survey on drug use and health: Detailed tables. Rockville, MD: Office of Applied Studies, US Department of Health and Human Services. Retrieved from http://oas.samhsa.gov/NSDUH/2K8NSDUH/tabs/Index.pdf.

Sullivan, M. J. L., Bishop, S. R., \& Pivik, J. (1995). The Pain Catastrophizing Scale: Development and validation. Psychological Assessment, 7, 524-532.

Sullivan, M. D., Turner, J. A., \& Romano, J. (1991). Chronic pain in primary care: Identification and management of psychosocial factors. Journal of Family Practice, 32, 193-199.

Swinkels-Meewisse, E. J. C. M., Swinkels, R. A. H. M., Verbeek, A. L. M., Vlaeyen, J. W. S., \& Oostendorp, R. A. B. (2003). Psychometric properties of the Tampa Scale for Kinesiophobia and the Fear-Avoidance Beliefs Questionnaire in acute low back pain. Manual Therapy, 8, 29-36.

Tabachnick, B. G., \& Fidell, L. S. (2007). Logistic regression. In Using multivariate statistics (5 ${ }^{\text {th }}$ ed.), (pp. 437-505). New York, NY: Pearson Education, Inc.

Tabachnick, B. G., \& Fidell, L. S. (2012). Cleaning up your act: Screening data prior to analysis. In Using multivariate statistics (6 ${ }^{\text {th }}$ ed.). Needham Heights, MA: Allyn \& Bacon. 
Tait, R. C., Chibnall, J. T., \& Krause, S. (1990). The Pain Disability Index: Psychometric properties. Pain, 40, 171-182.

Tamayo-Sarver, J. H., Hinze, S. W., Cydulka, R. K., \& Baker, D. W. (2003). Racial and ethnic disparities in emergency department analgesic prescription. American Journal of Public Health, 93, 2067-2073.

Tan, T., Barry, P, Reken, S., \& Baker, M. (2010). Pharmacological management of neuropathic pain in non-specialist settings: Summary of NICE guidance. British Medical Journal, 340, c1079.

Tan, G., Craine, M. H., Bair, M. J., Garcia, M. K., Giordano, J., Jensen, M. P.,...Tsao, J. C. I. (2007). Efficacy of selected complementary and alternative medicine interventions for chronic pain. Journal of Rehabilitation Research and Development, 44, 195-222.

Taylor, R. S. (2006). Spinal cord stimulation in complex regional pain syndrome and refractory neuropathic back and leg pain/failed back surgery syndrome: Results of a systematic review and meta-analysis. Journal of Pain and Symptom Management, 31 (Suppl), S13S19.

The National Center on Addiction and Substance Abuse at Columbia University. (2009). National survey of American attitudes on substance abuse XIV: Teens and parents. New York, NY: QEV Analytics, Ltd.

Thomsen, A. B., Sorensen, J., Sjogren, P., \& Eriksen, J. (2002). Chronic non-malignant pain patients and health economic consequences. European Journal of Pain, 6, 341-352.

Trescot, A., Glaser, S. E., Hansen, H., Benyamin, R., Patel, S., \& Manchikanti, L. (2008). Effectiveness of opioids in the treatment of chronic non-cancer pain. Pain Physician, Opioids Special Issue, 181-200. 
Turk, D. C., Swanson, K. S., \& Gatchel, R. J. (2008). Predicting opioid misuse by chronic pain patients: A systematic review and literature synthesis. Clinical Journal of Pain, 24, 497508.

Turk, D. C., Wilson, H. D., \& Cahana, A. (2011). Treatment of chronic non-cancer pain. Lancet, $377,2226-2235$.

Turner, J. A., Sears, J. M., \& Loeser, J. D. (2007). Programmable intrathecal opioid delivery systems for chronic noncancer pain: A systematic review of effectiveness and complications. Clinical Journal of Pain, 23, 180-195.

Upshur, C. C., Luckmann, R. S., \& Savageau, J. A. (2006). Primary care provider concerns and management of chronic pain in community clinic populations. Journal of General Internal Medicine, 21, 652-655.

U.S. Census Bureau. (2012). State and county quick facts: West Virginia. Retrieved September, 2012 from http://quickfacts.census.gov/qfd/states/54000.html.

van Orden, M., Hoffman, T., Haffmans, J., Spinhoven, P., \& Hoencamp, E. (2009). Collaborative mental health care versus care as usual in a primary care setting: A randomized controlled trial. Psychiatric Services, 60, 74-79.

van Tulder, M., Malmivaara, A., Hayden, J. A., \& Koes, B. (2007). Statistical significance versus clinical importance: Trials on exercise therapy for chronic low back pain as example. Spine, 32, 1785-1790.

Veehof, M. M., Maarten-Jan, O., Schreurs, K. M. G., \& Bohlmeijer, E. T. (2011). Acceptancebased interventions for the treatment of chronic pain: A systematic review and metaanalysis. Pain, 152, 533-542. 
Verhaak, P. F., Kerssens, J. J., Dekker, J., Sorbi, M. J., \& Bensing, J. M. (1998). Prevalence of chronic benign pain disorder among adults: A review of the literature. Pain, 77, 231-239.

Vonkeman, H.E., \& van de Laar, M. A. F. J. (2010). Nonsteroidal anti-inflammatory drugs: Adverse effects and their prevention. Seminars in Arthritis and Rheumatism, 39, 294-312.

Von Korff, M., Dworkin, S. F., Le Resche, L. (1990). Graded chronic pain status: An epidemiologic evaluation. Pain, 40, 279-291.

Von Korff, M., Dworkin, S. F., Le Resche, L., \& Kruger, A. (1988). An epidemiologic comparison of pain complaints. Pain, 32, 173-183.

Warner, M., Chen, L. H., \& Makuc, D. M. (2009). Increase in fatal poisonings involving opioid analgesics in the United States, 1999-2006. NCHS Data Brief, 22, 1-8.

Weaver, M. F., \& Schnoll, S. H. (2002). Opioid treatment of chronic pain in patients with addiction. Journal of Pain Palliative Care Pharmacotherapy, 16, 5-26.

Weisse, C. S., Sorum, P. C., Sanders, K. N., \& Syat, B. L. (2001). Do gender and race affect decisions about pain management? Journal of General Internal Medicine, 16, 211-217.

West Virginia Code. (2012). Article 9 Controlled Substances Monitoring. In Chapter 60A Uniform Controlled Substances Act. Retrieved from http://www.legis.state.wv.us/wvcode/ChapterEntire.cfm?chap=60a\&art=9.

White House Prescription Drug Abuse Prevention Plan. (2011). Epidemic: Responding to America's prescription drug abuse crisis. Retrieved from http://www.whitehouse.gov/sites/default/files/ondcp/policy-andresearch/rx_abuse_plan.pdf.

Witt, C. M., Ludtke, R., Wegscheider, K., \& Willich, S. N. (2010). Physician characteristics and variation in treatment outcomes: Are better qualified and experienced physicians more 
successful in treating patients with chronic pain with acupuncture? Journal of Pain, 11, 431-435.

Wolfert, M. Z., Gilson, A. M., Dahl, J. L., \& Cleary, J. F. (2010). Opioid analgesics for pain control: Wisconsin physicians' knowledge, beliefs, attitudes, and prescribing practices. Pain Medicine, 11, 425-434.

Ziegler, P. P. (2005). Addiction and the treatment of pain. Substance Use and Misuse, 40, 19451954.

Zou, K. H., Warfield, S. K., Fielding, J. R., Tempany, C. M. C., Wells, W. M., Kaus, M. R.,...Kikinis, R. (2003). Statistical validation based on parametric receiver operating characteristic analysis of continuous classification data. Academic Radiology, 10, 13591368.

Zuckerman, L., \& Ferrante, F. (1998). Nonopioid and opioid analgesics. In M. Ashburn, L. Rice (Eds.), The management of pain, (pp. 111-140). Philadelphia, PA: Churchill-Livingstone. 
Table 1

Frequencies and Percentages of Assigned Risk Status by Evaluator Training Level

\begin{tabular}{lcccc}
\hline \multicolumn{1}{c}{ Risk Status } & $\begin{array}{c}\text { Graduate } \\
\text { Student } \\
\text { Total }(\%)\end{array}$ & $\begin{array}{c}\text { Predoctoral } \\
\text { Intern } \\
\text { Total }(\%)\end{array}$ & $\begin{array}{c}\text { Postdoctoral } \\
\text { Fellow } \\
\text { Total }(\%)\end{array}$ & $\begin{array}{c}\text { Licensed } \\
\text { Psychologist } \\
\text { Total }(\%)\end{array}$ \\
\hline Low/Low-Moderate & $13(48.1)$ & $9(36.0)$ & $6(17.6)$ & $22(33.8)$ \\
Moderate/Moderate-High & $7(25.9)$ & $9(36.0)$ & $13(38.2)$ & $29(44.6)$ \\
High & $7(25.9)$ & $7(28.0)$ & $15(44.1)$ & $14(21.5)$ \\
Total & $27(100 / 17.9)$ & $25(100 / 16.6)$ & $34(100 / 22.5)$ & $65(100 / 43.0)$ \\
\end{tabular}

Note. In the three risk status levels, the number in parentheses represents the percent within each column group (e.g., $48.1 \%=$ percent of Graduate Students with evaluation outcomes in the low/low-moderate risk category). The numbers in parentheses for each Total reflect the group (column) total percentage, followed by the percentage of the overall total number of patients evaluated by each column group (e.g., 17.9\% = percent of total patients evaluated by a Graduate Student). 
Table 2

Frequencies and Percentages of Psychological Evaluator/Physician Training Level by Opioid Prescribing

\begin{tabular}{lcc}
\hline Evaluator/Physician Training Level & $\begin{array}{c}\text { Yes, Prescribed Opioid } \\
\text { Total }(\%)\end{array}$ & $\begin{array}{c}\text { No, Not Prescribed Opioid } \\
\text { Total }(\%)\end{array}$ \\
\hline Graduate Student & $17(19.3)$ & $10(15.9)$ \\
Predoctoral Intern & $20(22.7)$ & $5(7.9)$ \\
Postdoctoral Fellow & $20(22.7)$ & $14(22.2)$ \\
Licensed Psychologist & $31(35.2)$ & $34(54.0)$ \\
Total & $88(100 / 58.3)$ & $63(100 / 41.7)$ \\
& & $17(27.0)$ \\
Resident & $32(36.4)$ & $46(73.0)$ \\
Attending & $56(63.6)$ & $63(100 / 41.7)$ \\
Total & $88(100 / 58.3)$ & \\
\hline
\end{tabular}

Note. For the variables in each row (i.e., psychologist training level followed by physician training level), the number in parentheses represents the percent within each column group (e.g., $19.3 \%=$ percent of patients prescribed an opioid who had evaluations with a Graduate Student). The numbers in parentheses for each Total reflects the group (column) total percentage, followed by the percentage of the overall total number of patients prescribed or not prescribed an opioid (e.g., $58.3 \%=$ percent of total patients prescribed an opioid). 
Table 3

Inspecting Multicollinearity Assumption through Collinearity Statistics

\begin{tabular}{|c|c|c|}
\hline & Tolerance & Variance Inflation Factor \\
\hline Sex & .73 & 1.37 \\
\hline Race & .88 & 1.14 \\
\hline Age & .70 & 1.44 \\
\hline Risk Status & .46 & 2.17 \\
\hline Abuse history & .65 & 1.53 \\
\hline Smoking status & .78 & 1.29 \\
\hline Substance abuse & .58 & 1.71 \\
\hline Family substance abuse history & .71 & 1.40 \\
\hline Employment status & .75 & 1.33 \\
\hline Relationship status & .70 & 1.42 \\
\hline Education & .82 & 1.21 \\
\hline Mental health diagnoses & .84 & 1.19 \\
\hline Pain diagnoses & .90 & 1.11 \\
\hline
\end{tabular}


Table 3 (continued)

Inspecting Multicollinearity Assumption through Collinearity Statistics

Tolerance Variance Inflation Factor

Pain rating $(0-10)$

Duration of chronic pain

.73

1.36

Physician sex

.84

1.19

Physician training level

.87

1.15

SFMPQ

.61

1.65

PCS

.42

2.37

PDI

.62

1.60

SOAPP-R

.37

2.67

TSK

.56

1.80

BDI-II

Note SFMPQ = Short Form-McGill Pain Questionnaire; PCS = Pain Catastrophizing Scale; PDI

$=$ Pain Disability Index; SOAPP-R = Screener and Opioid Assessment for Patients with Pain,

Revised; TSK = Tampa Scale for Kinesiophobia; BDI-II = Beck Depression Inventory-II 
Table 4

Bivariate Correlations between Questionnaires

\begin{tabular}{|l|c|c|c|c|c|}
\hline & SF-MPQ & PCS & PDI & SOAPP-R & TSK \\
\hline PCS & $.43^{* *}$ & & & & \\
\hline PDI & $.35^{* *}$ & $.44^{* *}$ & & & \\
\hline SOAPP-R & $.33^{* *}$ & $.56^{* *}$ & $.33^{* *}$ & & \\
\hline TSK & $.28^{* *}$ & $.40^{* *}$ & $.40^{* *}$ & $.23^{*}$ & \\
\hline BDI-II & $.33^{* *}$ & $.50^{* *}$ & $.38^{* *}$ & $.65^{* *}$ & $.29 * *$ \\
\hline
\end{tabular}

Note. ${ }^{*}=$ significant at the $<.05$ level; $* *=$ significant at the $<.001$ level; SFMPQ $=$ Short Form-

McGill Pain Questionnaire; PCS = Pain Catastrophizing Scale; PDI = Pain Disability Index;

SOAPP-R = Screener and Opioid Assessment for Patients with Pain, Revised; TSK = Tampa

Scale for Kinesiophobia; BDI-II = Beck Depression Inventory-II 
Table 5

Missing Values by Self-Report Questionnaire

Questionnaire Number of missing items (\%)

Short Form-McGill Pain Questionnaire $90(3.9 \%)$

Pain Catastrophizing Scale $86(4.4 \%)$

Pain Disability Index $43(4.1 \%)$

Screener and Opioid Assessment for Patients with Pain-Revised $169(4.7 \%)$

Tampa Scale for Kinesiophobia $209(8.1 \%)$

Beck Depression Inventory-II $236(7.4 \%)$ 
Table 6

Patient Characteristics and Predictor Variables Descriptive Statistics for Study Sample (Continuous Variables)

\begin{tabular}{|c|c|c|c|c|}
\hline & Mean & Standard Deviation & Minimum & Maximum \\
\hline Age & 48.2 & 11.1 & 19 & 80 \\
\hline Pain rating & 7.6 & 1.8 & 0 & 10 \\
\hline Duration of pain (years) & 10.7 & 9.5 & .25 & 51 \\
\hline Times married & 1.5 & 1.1 & 0 & 7 \\
\hline Children & 2.3 & 1.7 & 0 & 10 \\
\hline SFMPQ & 21.4 & 9.7 & 0 & 45 \\
\hline PCS & 25.6 & 13.8 & 0 & 52 \\
\hline SOAPP-R & 17.2 & 11.3 & 0 & 74 \\
\hline BDI-II & 13.8 & 10.2 & 0 & 53 \\
\hline PDI & 40.4 & 15.0 & 0 & 70 \\
\hline TSK & 37.9 & 11.7 & 17 & 74 \\
\hline
\end{tabular}

Note. SFMPQ = Short Form-McGill Pain Questionnaire; PCS = Pain Catastrophizing Scale;

SOAPP-R = Screener and Opioid Assessment for Patients with Pain, Revised; BDI-II = Beck

Depression Inventory-II; PDI = Pain Disability Index; TSK = Tampa Scale for Kinesiophobia 
Table 7

Patient Characteristics and Predictor Variables Descriptive Statistics for Study Sample (Categorical Variables)

Total Percentage

Sex

Female

62

$41.1 \%$

Male

89

$58.9 \%$

Race

White

146

$96.7 \%$

Black

5

$3.3 \%$

Risk Status

Low/Low-Moderate

50

$33.1 \%$

Moderate/Moderate-High

58

$38.4 \%$

High

43

$28.5 \%$

Employment

Employed

70

$46.4 \%$

Disabled

81

$53.6 \%$

Relationship

Single/Divorced

Married/Partnered

Smoking Status

Yes

90

61

$59.6 \%$

No

Yes

No

84

$55.6 \%$

67

$44.4 \%$

Abuse History
48

93
$31.8 \%$

$61.6 \%$
$40.4 \%$ 
Table 7 (continued)

Patient Characteristics and Predictor Variables Descriptive Statistics for Study Sample (Categorical Variables)

Total Percentage

Education

$<$ High School

High School/GED

Associate's/Some College

Bachelor's or higher

Yes

No

Family Substance Abuse History

Yes

No

Resident

Attending

Substance Abuse History

Physician Training Level
29

$19.2 \%$

65

$43.0 \%$

30

$19.9 \%$

17

$11.3 \%$

58

$33.8 \%$

51

$38.4 \%$

102

$67.5 \%$

49

$32.5 \%$ 
Table 8

Differences in Demographic and Psychosocial Variables by Opioid Prescribing Group (Continuous Variables)

\begin{tabular}{lcccc}
\hline & $\begin{array}{c}\text { Not Prescribed } \\
\text { Opioid } \\
M(S D)\end{array}$ & $\begin{array}{c}\text { Prescribed } \\
\text { Opioid } \\
M(S D)\end{array}$ & $t(149)$ & $p$ \\
Age & $47.3(11.2)$ & $48.8(11.0)$ & -.80 & .43 \\
Pain rating (0-10)* & $8.0(1.8)$ & $7.4(1.7)$ & 1.95 & .05 \\
Duration of pain (years) & $10.6(10.1)$ & $10.8(9.1)$ & -.15 & .88 \\
Times married & $1.6(1.3)$ & $1.4(1.0)$ & 1.14 & .26 \\
Children & $2.4(1.8)$ & $2.2(1.6)$ & .65 & .43 \\
SFMPQ & $22.0(9.8)$ & $21.1(10.0)$ & .57 & .57 \\
PCS & $29.6(12.4)$ & $22.7(14.1)$ & 3.13 & .002 \\
SOAPP-R & $20.0(13.4)$ & $15.2(8.9)$ & 2.61 & .009 \\
BDI-II & $16.0(12.6)$ & $12.4(8.4)$ & 2.04 & .04 \\
PDI & $42.2(13.7)$ & $39.0(16.2)$ & 1.25 & .39 \\
TSK & $38.6(10.6)$ & $37.9(9.9)$ & .39 \\
\hline
\end{tabular}

Note. *Pain ratings measured from $0-10$, with 10 being the worst pain; SFMPQ $=$ Short FormMcGill Pain Questionnaire; PCS = Pain Catastrophizing Scale; SOAPP-R = Screener and Opioid Assessment for Patients with Pain, Revised; BDI-II = Beck Depression Inventory-II; PDI = Pain Disability Index; TSK = Tampa Scale for Kinesiophobia 
Table 9

Differences in Demographic and Psychosocial Variables by Opioid Prescribing Group (Categorical Variables)

\begin{tabular}{|c|c|c|c|c|c|}
\hline & & $\begin{array}{c}\text { Not Prescribed } \\
\text { Opioid } \\
\text { Total }(\%) \\
\end{array}$ & $\begin{array}{c}\text { Prescribed } \\
\text { Opioid } \\
\text { Total (\%) }\end{array}$ & $\chi^{2}$ & $p$ \\
\hline \multicolumn{6}{|l|}{ Sex } \\
\hline & Female & $36(57.1)$ & $53(60.2)$ & \multirow{2}{*}{.05} & \multirow{2}{*}{.83} \\
\hline & Male & 27 (42.9) & 35 (39.6) & & \\
\hline \multicolumn{6}{|c|}{ Race } \\
\hline & White & $59(93.7)$ & 87 (98.9) & \multirow[b]{2}{*}{1.70} & \multirow[b]{2}{*}{.19} \\
\hline & Black & $4(6.3)$ & $1(1.1)$ & & \\
\hline \multicolumn{6}{|c|}{ Employment } \\
\hline & Employed & $26(41.3)$ & $44(50.0)$ & \multirow[b]{2}{*}{.80} & \multirow[b]{2}{*}{.37} \\
\hline & Disabled & $37(58.7)$ & $44(50.0)$ & & \\
\hline \multicolumn{6}{|c|}{ Relationship } \\
\hline & Single/Divorced & $43(68.3)$ & $41(46.6)$ & \multirow{2}{*}{6.13} & \multirow{2}{*}{.01} \\
\hline & Married/Partnered & $20(31.7)$ & $47(53.4)$ & & \\
\hline \multicolumn{6}{|c|}{ Smoking Status } \\
\hline & Yes & $40(63.5)$ & $50(56.8)$ & \multirow{2}{*}{.43} & \multirow{2}{*}{.51} \\
\hline & No & $23(36.5)$ & $38(43.2)$ & & \\
\hline \multirow[t]{3}{*}{ Abus } & & & & & \multirow[b]{3}{*}{.02} \\
\hline & Yes & $27(46.6)$ & $21(25.3)$ & \multirow[b]{2}{*}{5.95} & \\
\hline & No & $31(53.4)$ & $62(74.7)$ & & \\
\hline \multicolumn{6}{|c|}{ Substance Abuse } \\
\hline & Yes & $37(58.7)$ & $20(22.7)$ & \multirow{2}{*}{18.75} & \multirow{2}{*}{$<.001$} \\
\hline & No & $26(41.3)$ & $68(77.3)$ & & \\
\hline
\end{tabular}

Note. For the variables in each row, the number in parentheses represents the percent within each column group (e.g., $57.1 \%=$ percent of females not prescribed an opioid). 
Table 9 (continued)

Differences in Demographic and Psychosocial Variables by Opioid Prescribing Group (Categorical Variables)

\begin{tabular}{|c|c|c|c|c|c|}
\hline & & $\begin{array}{l}\text { Not } \\
\text { Prescribed } \\
\text { Opioid } \\
\text { Total }(\%)\end{array}$ & $\begin{array}{l}\text { Prescribed } \\
\text { Opioid } \\
\text { Total }(\%)\end{array}$ & $\chi^{2}$ & $p$ \\
\hline \multirow{4}{*}{$\begin{array}{l}\text { Family } \\
\text { Substance Abuse }\end{array}$} & & & & \multirow{4}{*}{1.64} & \multirow{4}{*}{.20} \\
\hline & & & & & \\
\hline & Yes & $25(62.5)$ & $33(47.8)$ & & \\
\hline & No & $15(37.5)$ & $36(52.2)$ & & \\
\hline \multirow[t]{2}{*}{ Education } & & & & \multirow{5}{*}{10.75} & \multirow{5}{*}{.01} \\
\hline & $<$ High School & $20(33.3)$ & $9(11.1)$ & & \\
\hline \multirow{7}{*}{ Pain Diagnoses } & High School/GED & $24(40.0)$ & $41(50.6)$ & & \\
\hline & Associate's/Some College & $11(18.3)$ & $19(23.5)$ & & \\
\hline & Bachelor's or higher & $5(8.3)$ & $12(14.8)$ & & \\
\hline & & & & \multirow{6}{*}{.28} & \multirow{6}{*}{.99} \\
\hline & Musculoskeletal & $26(41.3)$ & $38(43.2)$ & & \\
\hline & Headache/Musculoskeletal & $15(23.8)$ & $19(21.6)$ & & \\
\hline & Abdominal/Chest & $8(12.7)$ & $13(14.8)$ & & \\
\hline \multirow{5}{*}{$\begin{array}{l}\text { Mental Health } \\
\text { Diagnoses }\end{array}$} & Neuropathic/Musculoskeletal & $7(11.1)$ & $9(10.2)$ & & \\
\hline & Chronic Widespread Pain & $7(11.1)$ & $9(10.2)$ & & \\
\hline & & & & \multirow{3}{*}{.51} & \multirow{3}{*}{.47} \\
\hline & Yes & $41(65.1)$ & $51(58.0)$ & & \\
\hline & No & $22(34.9)$ & $37(42.0)$ & & \\
\hline \multicolumn{6}{|c|}{$\begin{array}{l}\text { Note. For the variables in each row, the number in parentheses represents the percent within each } \\
\text { column group (e.g., } 62.5 \%=\text { percent of patients with a family history of substance abuse not }\end{array}$} \\
\hline
\end{tabular}


Table 10

Percentages of Study Sample with Various Chronic Pain Conditions and Mental Health Diagnoses

Total $(\%)$

Chronic Pain Conditions

Musculoskeletal

Headache/Musculoskeletal

Abdominal/Chest

Neuropathic/Musculoskeletal

Chronic Widespread Pain

Any condition

Anxiety

Depression

Bipolar Disorder

Psychotic Disorder

ADHD
$64(42.4 \%)$

$34(22.5 \%)$

$21(13.9 \%)$

$16(10.6 \%)$

$16(10.6 \%)$

$101(66.9 \%)$

$65(43.0 \%)$

$79(52.3 \%)$

$8(5.3 \%)$

$6(4.0 \%)$

$5(3.3 \%)$

Note. $\mathrm{ADHD}=$ Attention-Deficit Hyperactivity Disorder 
Table 11

Frequencies and Percentages for Opioid Prescribing Group and Risk Status

\begin{tabular}{lcc}
\hline & $\begin{array}{c}\text { Prescribed Opioid } \\
\text { Total }(\%)\end{array}$ & $\begin{array}{c}\text { Not Prescribed Opioid } \\
\text { Total }(\%)\end{array}$ \\
\hline Low/Low-Moderate & $43(48.9)$ & $7(11.1)$ \\
Moderate/Moderate-High & $34(38.6)$ & $24(38.1)$ \\
High & $11(12.5)$ & $32(50.8)$ \\
Total & $88(100 / 58.3)$ & $63(100 / 41.7)$ \\
\hline
\end{tabular}

Note. In the three risk status levels, the number in parentheses represents the percent within each column group (e.g., $48.9 \%=$ percent of patients prescribed an opioid in the low risk category). The number in parentheses for each Total reflects the group (column) total percentage, followed by the percentage of the overall total number of patients prescribed or not prescribed an opioid (e.g., $58.3 \%=$ percent of total patients prescribed an opioid). 
Table 12

Regression Model: Predicting Opioid Prescribing with Opioid Risk Status

\begin{tabular}{lcccc}
\hline Predictor Variable & $\begin{array}{c}\text { Unstandardized } \\
\text { Regression } \\
\text { Coefficient (B) }\end{array}$ & Standard Error & $\begin{array}{c}\text { Odds Ratio } \\
\text { Exp (B) }\end{array}$ & $\begin{array}{c}\text { Significance } \\
\text { Value }(p)\end{array}$ \\
\hline Risk Status & 1.44 & .27 & 4.22 & $<.001$ \\
\hline
\end{tabular}

Note. For this model, Cox $\&$ Snell $R^{2}=.22$, Nagelkerke $R^{2}=.29$. 
Table 13

Regression Models: Binary Logistic Regressions Predicting Opioid Prescribing with Single Significant Predictors

\begin{tabular}{|c|c|c|c|c|c|c|}
\hline Predictor Variable & $\begin{array}{l}\text { Unstandardized } \\
\text { Regression } \\
\text { Coefficient (B) } \\
\end{array}$ & $\begin{array}{l}\text { Standard } \\
\text { Error }\end{array}$ & $\begin{array}{l}\text { Odds Ratio } \\
\operatorname{Exp}(\mathrm{B})\end{array}$ & $\begin{array}{c}\text { Significance } \\
\text { Value }(p)\end{array}$ & $\begin{array}{c}\text { Cox \& Snell } R^{2} / \\
\text { Nagelkerke } R^{2}\end{array}$ & $\begin{array}{c}\text { Significance } \\
\text { Value }(p)\end{array}$ \\
\hline Substance Abuse & -1.58 & .36 & .21 & $<.001$ & $.13 / .17$ & $<.001$ \\
\hline Abuse & -.94 & .37 & .39 & .01 & $.05 / .06$ & .01 \\
\hline Education & .51 & .20 & 1.66 & .01 & $.05 / .06$ & .01 \\
\hline Relationship & .90 & .35 & 2.47 & .009 & $.05 / .06$ & .01 \\
\hline SOAPP-R & -.04 & .02 & .96 & .02 & $.05 / .06$ & .01 \\
\hline PCS & -.04 & .01 & .96 & .003 & $.06 / .08$ & .002 \\
\hline BDI-II & -.03 & .02 & .97 & .045 & $.03 / .04$ & .04 \\
\hline
\end{tabular}

Note. SOAPP-R = Screener and Opioid Assessment for Patients with Pain, Revised; PCS = Pain Catastrophizing Scale; BDI-II =

Beck Depression Inventory-II 
Table 14

Regression Models: Binary Logistic Regressions Predicting Opioid Prescribing with Single Non-Significant Predictors

\begin{tabular}{|c|c|c|c|c|c|c|}
\hline Predictor Variable & $\begin{array}{l}\text { Unstandardized } \\
\text { Regression } \\
\text { Coefficient (B) }\end{array}$ & $\begin{array}{l}\text { Standard } \\
\text { Error }\end{array}$ & $\begin{array}{l}\text { Odds Ratio } \\
\text { Exp (B) }\end{array}$ & $\begin{array}{l}\text { Significance } \\
\text { Value }(p)\end{array}$ & $\begin{array}{l}\text { Cox \& Snell } R^{2} \\
/ \text { Nagelkerke } R^{2}\end{array}$ & $\begin{array}{l}\text { Significance } \\
\text { Value }(p)\end{array}$ \\
\hline Age & .01 & .02 & 1.01 & .43 & $.004 / .01$ & .42 \\
\hline Sex & .13 & .34 & 1.14 & .70 & $.001 / .001$ & .70 \\
\hline Employment & -.35 & .33 & .70 & .29 & $.01 / .01$ & .29 \\
\hline Mental Health Condition & -.30 & .34 & .74 & .38 & $.01 / .01$ & .38 \\
\hline Family Substance Abuse & -.60 & .41 & .55 & .14 & $.02 / .03$ & .14 \\
\hline Smoking Status & -.28 & .34 & .76 & .41 & $.01 / .01$ & .41 \\
\hline Pain Category & & & & & $.002 / .002$ & .99 \\
\hline $\begin{array}{l}\text { Headache/ } \\
\text { Musculoskeletal }\end{array}$ & -.14 & .43 & .87 & .74 & & \\
\hline Abdominal/Chest & .11 & .52 & 1.11 & .84 & & \\
\hline $\begin{array}{l}\text { Neuropathic/ } \\
\text { Musculoskeletal }\end{array}$ & -.13 & .57 & .88 & .82 & & \\
\hline Chronic Widespread Pain & -.13 & .57 & .88 & .82 & & \\
\hline PCP Sex & .21 & .33 & 1.23 & .53 & $.003 / .003$ & .53 \\
\hline
\end{tabular}


Table 14 (continued)

Regression Models: Binary Logistic Regressions Predicting Opioid Prescribing with Single Non-Significant Predictors

\begin{tabular}{lcccccc}
\hline \multicolumn{1}{c}{ Predictor Variable } & $\begin{array}{c}\text { Unstandardized } \\
\text { Regression } \\
\text { Coefficient (B) }\end{array}$ & $\begin{array}{c}\text { Standard } \\
\text { Error }\end{array}$ & $\begin{array}{c}\text { Odds Ratio } \\
\text { Exp }(\mathrm{B})\end{array}$ & $\begin{array}{c}\text { Significance } \\
\text { Value }(p)\end{array}$ & $\begin{array}{c}\text { Cox \& Snell } R^{2} / \text { Nagelkerke } R^{2} \\
\text { Significance } \\
\text { Value }(p)\end{array}$ \\
\hline PCP Training & -.44 & .36 & .65 & .23 & $.01 / .01$ & .03 \\
SFMPQ & -.01 & .02 & .99 & .57 & $.002 / .003$ & $.01 / .02$ \\
PDI & -.01 & .01 & .99 & .02 & $.001 / .001$ \\
TSK & -.01 & .02 & .99 & .74 & .56 \\
\hline
\end{tabular}

Note PCP = Primary Care Physician; SFMPQ = Short Form McGill Pain Questionnaire; PDI = Pain Disability Index; TSK = Tampa Scale for Kinesiophobia 
Table 15

Regression Model: Predicting Opioid Prescribing with All Significant Predictors, excluding Risk Status

\begin{tabular}{lcccc}
\hline Predictor Variable & $\begin{array}{c}\text { Unstandardized } \\
\text { Regression } \\
\text { Coefficient (B) }\end{array}$ & Standard Error & $\begin{array}{c}\text { Odds Ratio } \\
\text { Exp (B) }\end{array}$ & $\begin{array}{c}\text { Significance } \\
\text { Value }(p)\end{array}$ \\
\hline Substance Abuse & -1.37 & .41 & .26 & .001 \\
Abuse & -.63 & .44 & .53 & .15 \\
Education & .37 & .23 & 1.44 & .11 \\
Relationship & .63 & .41 & 1.88 & .13 \\
BDI-II & -.004 & .03 & 1.00 & .90 \\
SOAPP-R & -.01 & .03 & .99 & .74 \\
PCS & -.01 & .02 & 1.00 & .48 \\
\hline
\end{tabular}

Note. For this model, Cox \& Snell $R^{2}=.19$, Nagelkerke $R^{2}=.26$; BDI-II $=$ Beck Depression Inventory-II; SOAPP-R = Screener and Opioid Assessment for Patients with Pain, Revised; PCS

$=$ Pain Catastrophizing Scale 
Table 16

Regression Model: Predicting Opioid Prescribing with Substance Abuse and Opioid Risk Status

\begin{tabular}{lcccc}
\hline Predictor Variable & $\begin{array}{c}\text { Unstandardized } \\
\text { Regression } \\
\text { Coefficient (B) }\end{array}$ & Standard Error & $\begin{array}{c}\text { Odds Ratio } \\
\text { Exp (B) }\end{array}$ & $\begin{array}{c}\text { Significance } \\
\text { Value }(p)\end{array}$ \\
\hline Substance Abuse & -.68 & .43 & .51 & .11 \\
Risk Status & 1.22 & .30 & 3.40 & $<.001$ \\
\hline
\end{tabular}

Note. For this model, Cox \& Snell $R^{2}=.23$, Nagelkerke $R^{2}=.31$ 
Table 17

Frequencies and Percentages for Primary Care Physician Training Level and Risk Status

\begin{tabular}{lcc}
\hline & $\begin{array}{c}\text { Attending } \\
\text { Total }(\%)\end{array}$ & $\begin{array}{c}\text { Resident } \\
\text { Total }(\%)\end{array}$ \\
\hline Low/Low-Moderate & $14(28.6)$ & $36(35.3)$ \\
Moderate/Moderate-High & $20(40.8)$ & $38(37.3)$ \\
High & $15(30.6)$ & $28(27.5)$ \\
Total & $49(100 / 32.5)$ & $102(100 / 67.5)$ \\
\hline
\end{tabular}

Note. In the three risk status levels, the number in parentheses represents the percent within each column group (e.g., $28.6 \%=$ percent of patients assigned low/low-moderate risk referred by attending physicians). The numbers in parentheses for each Total reflects the group (column) total percentage, followed by the percentage of the overall total number of patients referred by each training level (e.g., $32.5 \%=$ percent of total patients referred by attending physicians). 


\section{Appendix A}

\section{Non-Opioid Treatments for Chronic Pain}

Pharmacological treatments. Physician guidelines provide clear suggestions in the treatment of chronic pain based on intensity (Katz, 2008). When treating mild pain, acetaminophen and nonsteroidal anti-inflammatory drugs (NSAIDs; e.g., aspirin, naproxen) are recommended because there is a ceiling effect to the analgesia and they do not produce tolerance or physical dependence; however, there is increased risk for gastrointestinal ulcers, serious cardiovascular events, hypertension, acute renal failure, and worsening of preexisting heart failure (Vonkeman \& van de Laar, 2010). These adverse effects can be prevented by limiting NSAID dosage and duration. Acetaminophen and NSAIDs are effective at relieving pain resulting from a variety of problems including trauma, arthritis, surgery, and cancer (Carr \& Goudas, 1999; Zuckerman \& Ferrante, 1998). Treating moderate or severe chronic pain without opioids is more complicated. Combination therapies can enhance the effects of non-opioid analgesics, especially when treating neuropathic pain, which is damage or disease affecting the somatosensory system (Guay, 2001). The most effective adjuvant therapy is tricyclic antidepressants (Guay, 2001). Tricyclic antidepressants are not FDA-approved for pain treatment; however, several studies have shown their effectiveness for arthritis, diabetic neuropathy, postherpetic neuralgia, tension headache, migraine, fibromyalgia, low back pain, and pelvic pain (Barkin, Schwer, \& Barkin, 2007; Rosenquist, 2013). A second adjunctive treatment is anticonvulsants, which are effective at relieving shooting pain associated with peripheral nerve damage (Guay, 2001). Anticonvulsants are effective in alleviating the pain associated with fibromyalgia and neuropathic pain, with some support for use in patients with low-back pain due to radiculopathy (Attal et al., 2010; Dworkin et al., 2010; Crofford et al., 2005; Tan, Barry, 
Reken, \& Baker, 2010). Skeletal muscle relaxants often are prescribed as adjuvant medications for short-term relief due to the sedative side effects. The long term use of muscle relaxants has not been shown to be an effective treatment for chronic pain; however, they are superior to placebo for mild to severe muscle spasms often associated with a variety of pain conditions (See \& Ginzburg, 2008). Finally, topical agents have been utilized when the pain in localized and are advantageous in that the user can avoid systemic side-effects (Turk, Wilson, \& Cahana, 2011). Topical agents have demonstrated effective pain relief as compared to placebo for neuropathic pain and musculoskeletal disorders (Mason et al., 2004). These non-opioid pharmacological options provide health care providers with greater flexibility when treating chronic pain and are effective at alleviating mild to moderate pain (Guay, 2001).

Interventional treatments. Interventional treatments include anesthetic injection therapy, surgical intervention, and implantable devices, all with the purpose of locating an individual's source of pain and providing pain relief (Turk et al., 2011). Injection therapy utilizes nerve blocks, which deliver various anesthetics to nerves and muscles to interrupt pain messages in the body, reduce inflammation, or eliminate the neurons at the site of the pain (Turk et al., 2011). The most common injection for pain management is an epidural steroid injection, which is most effective in patients with radiculopathy with prolapsed lumbar disc (i.e., nerve root damage, which can cause pain in the arms, hands, or feet) and less so in those with non-specific low-back pain (Chou, Atlas, Stanos, \& Rosenquist, 2009; Manchikanti, 2004). The second most common injection is the facet injection, which includes a long-lasting corticosteroid (e.g., triamcinolone or methylprednisolone) and an anesthetic numbing agent (e.g., lidocaine or bupivacaine; Manchikanti, 2004). There are mixed findings in regard to the effectiveness of injections, especially for long-term use. A review conducted by Luijsterburg et al. (2007), 
found injections were not shown to be clearly effective for use in lumbosacral radicular syndrome (i.e., low back pain that radiates into the buttock or down the leg); however, Chou and colleagues (2009) determined injections are useful in facet joint pain. The general consensus in the literature is that the use of an injection treatment regimen is most effective for facet joint pain, discogenic low-back pain, and in radiculopathy with prolapsed lumbar discs (Chou et al., 2009).

Surgical intervention refers to procedures such as lumbar fusions, artificial disc replacement, discectomy for radiculopathy with herniated lumbar disc, decompressive laminectomy for spinal stenosis, and implantation of an interspinous spacer device (Turk et al., 2011). From 1990 to 2001, there has been an increase in spinal surgeries for chronic pain patients, with lumbar fusion procedures increasing 220\% (Deyo, Gray, Kreuter, Mirza, \& Martin, 2005). While the rate of surgeries has increased, the evidence supporting the effectiveness of spinal surgeries in pain reduction remains poor to fair. Studies have found that there can be initial significant pain reduction; however, benefits diminish over time, with one study reporting $41 \%$ of patients with no change or worsened quality of life approximately five years following the procedure (DeBerard, Masters, Colledge, Schleusener, \& Schlegel, 2001; Fritzell, Hagg, Wessberg, \& Nordwall, 2001). For patients with chronic non-cancer pain, there are no guidelines that suggest which patients are most likely to benefit from spinal surgery, and as a result the outcomes on pain reduction are unpredictable.

Another interventional treatment involves the implantation of electrodes or intrathecal drug delivery devices on or near the spine (Turk et al., 2011). The electrodes act to inhibit pain signals by stimulating peripheral nerves, which modulate pain (Turk et al., 2011). This technique has been shown to reduce pain, improve quality of life, reduce the use of analgesics, 
and result in patients returning to work; however, these results are limited to selected patients with refractory neuropathic pain (Taylor, 2006). Epidural and intrathecal devices provide targeted drug delivery, which enables patients to experience pain relief with a small fraction of an oral medication dose (Nance \& Meythaler, 1999). Turner, Sears, and Loeser (2007) conducted a systematic review and concluded that patients typically experience moderate reductions in pain and improvements in functioning; however, the long-term effectiveness is unclear. Implantable devices should be considered after oral medication, surgery, and injection procedures have not provided adequate pain reduction due to the need for routine monitoring, high cost, and need for replacement and maintenance of devices (Turk et al., 2011).

A less invasive alternative to intrathecal drug delivery devices is transcutaneous electric nerve stimulation. This technique utilizes electrodes placed on the skin near the spine, which deliver electrical stimulation to reduce pain through nociceptive inhibition at the presynaptic level in the dorsal horn, limiting the transmission of pain signals (Nnoaham \& Kumbang, 2008). Systematic reviews and meta-analyses resulted in mixed findings on the effectiveness for transcutaneous electric nerve stimulation on pain reduction, which in part is due to poor study methodology (Johnson \& Martinson, 2007; Khadilkar, Odebiyi, Brosseau, \& Wells, 2008; Nnoaham \& Kumbang, 2008).

Physical, rehabilitation, and psychological interventions. Exercise interventions have been shown to decrease pain by approximately $30 \%$ and improve function by approximately 20\% (van Tulder, Malmivaara, Hayden, \& Koes, 2007). Exercise interventions also have been shown to affect work disability status, increasing returns to work (Schonstein, Kenny, Keating, \& Koes, 2003; Oesch, Kool, Hagen, \& Bachmann, 2010). One problem with the success of these 
interventions is patient adherence, which potentially can be mitigated through psychological intervention.

The most common psychotherapeutic techniques utilized for chronic pain patients include cognitive-behavioral strategies (Turk et al., 2011). Specific strategies commonly employed are coping techniques, cognitive restructuring, and relaxation techniques. The results of several meta-analyses and systematic reviews suggest that psychological treatment results in moderate improvements in pain reduction and physical and emotional functioning (Dixon, Keefe, Scipio, Perri, \& Abernethy, 2007; Henschke et al., 2010; Hoffman, Papas, Chatkoff, \& Kerns, 2007; Jensen \& Patterson, 2006; Montgomery, DuHamel, \& Redd, 2000; Morley, Eccleston, \& Williams, 1999). Because a portion of patients do not respond to cognitive-behavioral treatment, a second psychotherapeutic strategy of acceptance-based interventions has been employed for chronic pain patients. These techniques emphasize acceptance of the pain rather than attempting to fight or control it; to recognize and accept that the pain is a part of life and cannot be completely eliminated. This approach utilizes mindfulness and meditation techniques to reduce stress and pain (Kabat-Zinn, 1990). A systematic review and meta-analysis revealed that acceptance-based interventions are equivalent in effectiveness to cognitive-behavioral treatment, and may be a good alternative for those who do not respond to cognitive-behavioral techniques (Veehof, Maarten-Jan, Schreurs, \& Bohlmeijer, 2011).

Integration of physical and psychological treatments into a singular interdisciplinary pain rehabilitation program results in significant pain reduction (Guzman et al., 2001; Hoffman et al., 2007; Morley et al., 1999) and a decrease in prescription pain medication usage (Hoffman et al., 2007). Other studies have reported significant reductions in health care use after rehabilitation programs (Flor, Fydrich, \& Turk, 1992), and reduction in social transfers and benefits (i.e., 
welfare benefits, sickness benefit, and pensions; Thomsen, Sorensen, Sjogren, \& Eriksen, 2002), which has not been shown to be possible through pharmacological or invasive treatment (Nachemson, 1992). Additionally, in two of the meta-analyses conducted, results suggest that the long-term effects on return to work for patients treated in an interdisciplinary rehabilitation program were superior to those of other active treatments (Flor et al., 1992; Hoffman et al., 2007).

Complementary and alternative interventions. The most popular complementary and alternative treatments offered include spinal manipulations, massage therapy, and acupuncture. These techniques are not commonly associated with conventional medicine; however, research has demonstrated that these techniques are at least minimally effective in reducing pain (Turk et al., 2011). Spinal manipulations (i.e., chiropractic adjustments) are most commonly used for low-back pain. Based on two systematic reviews, researchers concluded that spinal manipulations are more effective than "placebo" spinal manipulations, bed rest, or traction (Tan et al., 2007). Massage therapy seems to have benefits for low-back and shoulder pain and potentially beneficial for fibromyalgia and neck pain (Tan et al., 2007); however, it is difficult to draw conclusions because of the wide variations in massage techniques. Of all of the complementary and alternative interventions, acupuncture has the most support for its use with chronic pain patients. Acupuncture has been shown to be effective for the treatment of chronic low-back pain (Furlan et al., 2005; Haake et al., 2007; Manheimer, White, Berman, Forys, \& Ernst, 2005; Witt, Ludtke, Wegscheider, \& Willich, 2010) with possible pain reduction benefits for fibromyalgia and neck pain (Gilron \& Max, 2001). While acupuncture helps to reduce pain, it has not been shown to be effective in improving functioning, physically or emotionally (Turk et al., 2011). 
Appendix B

Flow sheet for Chronic Opioid Therapy: WVU Department of Family Medicine NEW PATIENTS TO CLINIC:

- No opioids written at first visit

- Explain process to patients and give information sheet on narcotics prior to check out PRIOR TO PRESCRIBING OPIOIDS:

- Previous records received from provider and reviewed

- Urine drug screen

- Physical exam and review of diagnostic studies

- Diagnosis of pain condition determined

- WV Board of Pharmacy review

- Refer to Family Medicine psychologists for pain evaluation

PAIN ASSESSMENT (BY PSYCHOLOGIST)

- Self-report questionnaires assess:

- Quality, intensity, and duration of pain

- Functioning affected by pain

- Negative cognitions about pain

- Fear of activity and movement

- Risk for future misuse of opioids

- Current behaviors indicating medication misuse

- Mood

- Clinical Interview

- Pain triggers 
- Goals for pain and function

- Impact of pain on functioning

- Pain treatment history

- Social and family history

- Substance abuse history for patient and family

\section{IF PRESCRIBING OPIOID...}

- Controlled substance agreement signed

- Treatment plan includes non-opioid options (PT, TCA, anti-seizure med, Tai Chi, CBT)

- Document plan in chart

- All controlled substances scripts printed electronically

- No other CNS depressants (i.e, Benzodiazepines or ETOH)

- If resident physician, inform attending

PERIODIC ASSESSMENT FOR ALL PATIENTS ON CHRONIC OPIOIDS

- Random Drug Screen every 4-6 months or as physician requests

- Pain, functioning, mood measures

- Verify adherence to all treatment (not solely opioids)

- Verify that patient is not receiving opioids from other providers or locations (review Electronic Medical Records

- Board of Pharmacy required at least annually 
Appendix C

Demographics Form

Today's date:

NAME:

DATE OF BIRTH:

AGE:

Are you: (Circle one) Single Married Separated Divorced Widowed

Number of Children:

How many times have you been married?

If married, Spouse's occupation:

Are you (circle one): Working Retired Disabled Student Volunteering Other

What type of work do you do?

Person to contact in emergency :

Phone:

Who lives with you?

If we need to contact you, is it $\mathrm{OK}$ to call you at home?

Work?

Is it $\mathrm{OK}$ to leave a message?

If yes, at what number?

Family Doctor:

List of Medications:

Reason for visit today?

How long has pain been a problem for you?

Which of these techniques have you already tried? How much did it help?

\begin{tabular}{|l|c|c|c|c|c|}
\hline & $\begin{array}{c}1 \\
\text { (none) }\end{array}$ & $\mathbf{2}$ & $\begin{array}{c}\mathbf{3} \\
\text { (some) }\end{array}$ & $\mathbf{4}$ & $\begin{array}{c}\mathbf{5} \\
\text { (a lot) }\end{array}$ \\
\hline Physical Therapy & & & & & \\
\hline Surgery & & & & & \\
\hline Medication & & & & & \\
\hline Massage & & & & & \\
\hline Exercise & & & & & \\
\hline Tai Chi/Yoga & & & & & \\
\hline Chiropractor & & & & & \\
\hline
\end{tabular}

Caffeine use (Circle all that apply): $\quad$ Coffee $\quad$ Tea $\quad$ Soda No-Doz

Alcohol use: Daily Weekly Monthly

How much?

Nicotine Use: Cigarettes/day: Packs/day Years Used 
Have you ever tried to quit? Yes__ No Would you like to try to quit? Yes__ No

Is alcohol or drug use causing you any problems in your life? Yes No

Have you ever tried to hurt yourself? Yes

Are there guns in your home?

(When?

) No

No

Highest Grade Completed:

Where were you raised?

Who raised you?

How long have you lived in this area?

Was there any violence in your home when you were a child?

Do you have a religious affiliation? YES__ NO

If yes, how often do you attend church services?

Are there any cultural or ethnic issues that would be important for me to understand about you? YES $\mathrm{NO}$

Have you ever served in the military? YES

$\mathrm{NO}$

What do you do for fun?

Please place an X in the NOW column for any of the following symptoms you are currently having, and place an $\mathrm{X}$ in the PAST column for any of the symptoms you have had in the past.

\begin{tabular}{|c|c|c|c|}
\hline NOW & PAST & NOW PAST & \\
\hline & _ Sad Most of the Time & $\longrightarrow$ & Mood Swings \\
\hline & Loss of Energy & 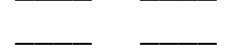 & Too Much Energy \\
\hline & Not Enjoying Things & & Spending Too Much Money \\
\hline & Loss of Sex Drive & & Feeling Nervous \\
\hline & Excessive Sleep & & Difficulty with Sleep \\
\hline & Hearing voices in your head & & Angry Outbursts \\
\hline & Worry too much & & Unusual thoughts \\
\hline & Problems Concentrating & - & Panic attacks \\
\hline & Feeling Shaky & & Thoughts you can't get out of your head \\
\hline & Don't want to live & 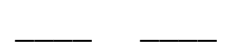 & Feeling like you're being watched or followed \\
\hline
\end{tabular}

If you could change 3 things about yourself or your situation, what would you pick?

1) Most important:

2) Next important:

3) Important:

Is there anything else you would like us to know about you or your situation? 


\section{Appendix D}

\section{Short Form-McGill Pain Questionnaire}

Some of these words describe your present pain. Please mark an intensity rating for each word. If a word does not describe your pain, rate it " 0 " (none). If a word does describe your pain, rate the intensity of that quality with "1" (mild), "2" (moderate), or "3" (severe). Make your rating by placing a mark in the appropriate box.

\begin{tabular}{|l|l|l|l|l|}
\hline \multicolumn{1}{|c|}{ Throbbing } & $\begin{array}{c}\text { None } \\
\text { (0) }\end{array}$ & $\begin{array}{c}\text { Mild } \\
\text { (1) }\end{array}$ & $\begin{array}{c}\text { Moderate } \\
\text { (2) }\end{array}$ & $\begin{array}{c}\text { Severe } \\
\text { (3) }\end{array}$ \\
\hline 2. Shooting & & & & \\
\hline 3. Stabbing & & & & \\
\hline 4. Sharp & & & & \\
\hline 5. Cramping & & & & \\
\hline 6. Gnawing & & & & \\
\hline 7. Hot-Burning & & & & \\
\hline 8. Aching & & & & \\
\hline 9. Heavy & & & & \\
\hline 10. Tender & & & & \\
\hline 11. Splitting & & & & \\
\hline 12. Tiring-Exhausting & & & & \\
\hline 13. Sickening & & & & \\
\hline 14. Fearful & & & & \\
\hline 15. Punishing-Cruel & & & & \\
\hline
\end{tabular}

Mark the intensity of your present pain on the following scale:

$\square$ No Pain $\quad(0)$

Mild

Discomforting

Distressing

Horrible

Excruciating 


\section{Appendix E}

\section{Pain Disability Index}

The rating scales below are designed to measure the degree to which several aspects of your life are presently disrupted by persistent pain. In other words, we would like to know how much your pain is preventing you from doing what you would normally do, or from doing it as well as you normally would. Respond to each category by indicating the overall impact of pain in your life, not just when the pain is at its worst.

For each of the 7 categories of life activity listed, please circle the number on the scale which describes the level of disability you typically experience. A score of 0 means no disability at all, and a score of 10 signifies that all of the activities in which you would normally be involved have been totally disrupted or prevented by your pain.

\begin{tabular}{|c|c|c|c|c|c|c|c|c|c|c|c|}
\hline \multicolumn{10}{|c|}{$\begin{array}{c}\text { No } \\
\text { Disability }\end{array}$} & \multicolumn{2}{|c|}{$\begin{array}{c}\text { Total } \\
\text { Disability }\end{array}$} \\
\hline $\begin{array}{l}\text { 1. Family/Home Responsibilities } \\
\text { This category refers to activities related to the home } \\
\text { or family. It includes chores or duties performed } \\
\text { around the house (e.g., yard work) and errands or } \\
\text { favors for other family members (e.g., driving the } \\
\text { children to school). }\end{array}$ & 0 & 1 & 2 & 3 & 4 & 5 & 6 & 7 & 8 & 9 & 10 \\
\hline $\begin{array}{l}\text { 2. Recreation } \\
\text { This category includes hobbies, sports, and other } \\
\text { leisure time activities. }\end{array}$ & 0 & 1 & 2 & 3 & 4 & 5 & 6 & 7 & 8 & 9 & 10 \\
\hline $\begin{array}{l}\text { 3. Social Activity } \\
\text { This category refers to activities which involve } \\
\text { participation with friends and acquaintances other } \\
\text { than family members. It includes parties, theatre, } \\
\text { concerts, dining out, and other social functions. }\end{array}$ & 0 & 1 & 2 & 3 & 4 & 5 & 6 & 7 & 8 & 9 & 10 \\
\hline $\begin{array}{l}\text { 4. Occupation } \\
\text { This category refers to activities that are part of or } \\
\text { directly related to one's job. This includes non- } \\
\text { paying jobs such as that of a housewife or volunteer } \\
\text { work. }\end{array}$ & 0 & 1 & 2 & 3 & 4 & 5 & 6 & 7 & 8 & 9 & 10 \\
\hline $\begin{array}{l}\text { 5. Sexual Behavior } \\
\text { This category refers to the frequency and quality of } \\
\text { one's sex life. }\end{array}$ & 0 & 1 & 2 & 3 & 4 & 5 & 6 & 7 & 8 & 9 & 10 \\
\hline $\begin{array}{l}\text { 6. Self-Care } \\
\text { This category includes activities which involve } \\
\text { personal maintenance and independent daily living } \\
\text { (e.g., taking a shower, getting dressed, etc.). }\end{array}$ & 0 & 1 & 2 & 3 & 4 & 5 & 6 & 7 & 8 & 9 & 10 \\
\hline $\begin{array}{l}\text { 7. Life-Support Activity } \\
\text { This category refers to basic life-supporting } \\
\text { behaviors such as eating, sleeping, and breathing. }\end{array}$ & 0 & 1 & 2 & 3 & 4 & 5 & 6 & 7 & 8 & 9 & 10 \\
\hline
\end{tabular}




\section{Appendix F}

\section{Pain Catastrophizing Scale}

Everyone experiences painful situations as some point in their lives. Such experiences may include headaches, tooth pain, joint or muscle pain. People are often exposed to situations that may cause pain such as illness, injury, dental procedures, or surgery.

We are interested in the types of thoughts and feelings that you have when you are in pain. Listed below are 13 statements describing different thoughts and feelings that may be associated with pain. Using the following scale, please circle the degree to which you have these thoughts and feelings when you are experience pain.

\begin{tabular}{|c|c|c|c|c|c|}
\hline & $\begin{array}{c}\text { Not } \\
\text { at All }\end{array}$ & $\begin{array}{c}\text { To a } \\
\text { Slight Degree } \\
\end{array}$ & $\begin{array}{c}\text { To a Moderate } \\
\text { Degree }\end{array}$ & $\begin{array}{c}\text { To a } \\
\text { Great Deal } \\
\end{array}$ & $\begin{array}{c}\text { All the } \\
\text { time }\end{array}$ \\
\hline 1. I worry all the time about whether the pain will end. & 0 & 1 & 2 & 3 & 4 \\
\hline 2. I feel I can't go on. & 0 & 1 & 2 & 3 & 4 \\
\hline 3. It's terrible and I think it's never going to get any better. & 0 & 1 & 2 & 3 & 4 \\
\hline 4. It's awful and I feel that it overwhelms me. & 0 & 1 & 2 & 3 & 4 \\
\hline 5. I feel I can't stand it anymore. & 0 & 1 & 2 & 3 & 4 \\
\hline 6. I become afraid that the pain will get worse. & 0 & 1 & 2 & 3 & 4 \\
\hline 7. I keep thinking of other painful events. & 0 & 1 & 2 & 3 & 4 \\
\hline 8. I anxiously want the pain to go away. & 0 & 1 & 2 & 3 & 4 \\
\hline 9. I can't seem to keep it out of my mind. & 0 & 1 & 2 & 3 & 4 \\
\hline 10. I keep thinking about how much it hurts. & 0 & 1 & 2 & 3 & 4 \\
\hline 11. I keep thinking about how badly I want the pain to stop. & 0 & 1 & 2 & 3 & 4 \\
\hline 12. There's nothing I can do to reduce the intensity of the pain. & 0 & 1 & 2 & 3 & 4 \\
\hline 13. I wonder whether something serious may happen. & 0 & 1 & 2 & 3 & 4 \\
\hline
\end{tabular}




\section{Appendix G}

\section{Tampa Scale for Kinesiophobia}

Please read each of the following statements and mark the number that better represents your feelings.

\begin{tabular}{|c|c|c|c|c|}
\hline & $\begin{array}{l}\text { Strongly } \\
\text { Disagree }\end{array}$ & $\begin{array}{l}\text { Somewhat } \\
\text { Disagree }\end{array}$ & $\begin{array}{c}\text { Somewhat } \\
\text { Agree }\end{array}$ & $\begin{array}{l}\text { Strongly } \\
\text { Agree }\end{array}$ \\
\hline 1. I'm afraid that I might injure myself if I exercise. & 1 & 2 & 3 & 4 \\
\hline 2. If I were to try and overcome it, my pain would increase. & 1 & 2 & 3 & 4 \\
\hline $\begin{array}{l}\text { 3. My body is telling me I have something dangerously } \\
\text { wrong. }\end{array}$ & 1 & 2 & 3 & 4 \\
\hline 4. My pain would probably be relieved if I were to exercise. & 1 & 2 & 3 & 4 \\
\hline $\begin{array}{l}\text { 5. People aren't taking my medical condition seriously } \\
\text { enough. }\end{array}$ & 1 & 2 & 3 & 4 \\
\hline $\begin{array}{l}\text { 6. My accident has put my body at risk for the rest of my } \\
\text { life. }\end{array}$ & 1 & 2 & 3 & 4 \\
\hline 7. Pain always means I have injured my body. & 1 & 2 & 3 & 4 \\
\hline $\begin{array}{l}\text { 8. Just because something aggravates my body does not } \\
\text { mean it is dangerous. }\end{array}$ & 1 & 2 & 3 & 4 \\
\hline 9. I am afraid that I might injure myself accidently. & 1 & 2 & 3 & 4 \\
\hline $\begin{array}{l}\text { 10. Simply being careful that I do not make any unnecessary } \\
\text { movements is the safest thing I can do to prevent my pain } \\
\text { from worsening. }\end{array}$ & 1 & 2 & 3 & 4 \\
\hline $\begin{array}{l}\text { 11. I wouldn't have this much pain if there weren't something } \\
\text { potentially dangerous going on in my body. }\end{array}$ & 1 & 2 & 3 & 4 \\
\hline $\begin{array}{l}\text { 12. Although my condition is painful, I would be better off if } \\
\text { I were physically active. }\end{array}$ & 1 & 2 & 3 & 4 \\
\hline $\begin{array}{l}\text { 13. Pain lets me know when to stop exercising so that I don't } \\
\text { injure myself. }\end{array}$ & 1 & 2 & 3 & 4 \\
\hline $\begin{array}{l}\text { 14. It's really not safe for a person with a condition like mine } \\
\text { to be physically active. }\end{array}$ & 1 & 2 & 3 & 4 \\
\hline $\begin{array}{l}\text { 15. I can't do all the things normal people do because it's too } \\
\text { easy for me to get injured. }\end{array}$ & 1 & 2 & 3 & 4 \\
\hline $\begin{array}{l}\text { 16. Even though something is causing me a lot of pain, I don't } \\
\text { think it's actually dangerous. }\end{array}$ & 1 & 2 & 3 & 4 \\
\hline 17. No one should have to exercise when s/he is in pain. & 1 & 2 & 3 & 4 \\
\hline
\end{tabular}




\section{Appendix $\mathrm{H}$}

Screener and Opioid Assessment for Patients with Pain-Revised

\begin{tabular}{|c|c|c|c|c|c|}
\hline & Never & Seldom & $\begin{array}{c}\text { Some- } \\
\text { times }\end{array}$ & Often & $\begin{array}{c}\text { Very } \\
\text { Often }\end{array}$ \\
\hline 1. How often do you have mood swings? & 0 & 1 & 2 & 3 & 4 \\
\hline 2. How often have you felt the need for higher doses of medication to treat your pain? & 0 & 1 & 2 & 3 & 4 \\
\hline 3. How often have you felt impatient with your doctors? & 0 & 1 & 2 & 3 & 4 \\
\hline 4. How often have you felt that things are just too overwhelming that you can't handle them? & 0 & 1 & 2 & 3 & 4 \\
\hline 5. How often is there tension in the home? & 0 & 1 & 2 & 3 & 4 \\
\hline 6. How often have you counted pain pills to see how many are remaining? & 0 & 1 & 2 & 3 & 4 \\
\hline 7. How often have you been concerned that people will judge you for taking pain medication? & 0 & 1 & 2 & 3 & 4 \\
\hline 8. How often do you feel bored? & 0 & 1 & 2 & 3 & 4 \\
\hline 9. How often have you taken more pain medication than you were supposed to? & 0 & 1 & 2 & 3 & 4 \\
\hline 10. How often have you worried about being left alone? & 0 & 1 & 2 & 3 & 4 \\
\hline 11. How often have you felt a craving for medication? & 0 & 1 & 2 & 3 & 4 \\
\hline 12. How often have others expressed concern over your use of medication? & 0 & 1 & 2 & 3 & 4 \\
\hline 13. How often have any of your close friends had a problem with alcohol or drugs? & 0 & 1 & 2 & 3 & 4 \\
\hline 14. How often have others told you that you had a bad temper? & 0 & 1 & 2 & 3 & 4 \\
\hline 15. How often have you felt consumed by the need to get pain medication? & 0 & 1 & 2 & 3 & 4 \\
\hline 16. How often have you run out of pain medication early? & 0 & 1 & 2 & 3 & 4 \\
\hline 17. How often have others kept you from getting what you deserved? & 0 & 1 & 2 & 3 & 4 \\
\hline 18. How often in your lifetime have you had legal problems or been arrested? & 0 & 1 & 2 & 3 & 4 \\
\hline 19. How often have you attended an AA or NA meeting? & 0 & 1 & 2 & 3 & 4 \\
\hline 20. How often have you been in an argument that was so out of control that someone got hurt? & 0 & 1 & 2 & 3 & 4 \\
\hline 21. How often have you been sexually abused? & 0 & 1 & 2 & 3 & 4 \\
\hline 22. How often have others suggested that you have a drug or alcohol problem? & 0 & 1 & 2 & 3 & 4 \\
\hline 23. How often have you had to borrow pain medications from your family or friends? & 0 & 1 & 2 & 3 & 4 \\
\hline 24. How often have you been treated for an alcohol or drug problem? & 0 & 1 & 2 & 3 & 4 \\
\hline
\end{tabular}

